\title{
Methan- und Sauerstoffhaushalt im mesotrophen Lungernsee
}

\author{
Von P. Bossard und R. Gächter \\ Eidg. Anstalt für Wasserversorgung, Abwasserreinigung und Gewässerschutz (EAWAG), CH-8600 \\ Dübendorf
}

Manuskript eingegangen am 7. August 1981

\begin{abstract}
Prealpine Lake Lungern shows in spite of low primary production rates $\left(120 \mathrm{~g} \mathrm{C} / \mathrm{m}^{2} \cdot\right.$ year $)$ and full winter overturns a complete oxygen depletion in the deepest hypolimnion (65-70 m below surface) towards the end of summer stagnation.

Periodical examinations of $\mathrm{O}_{2-}$ and $\mathrm{CH}_{4}$-concentrations, $\mathrm{CH}_{4}$-oxidation rates and temperature in the water column during 1975/76 enabled an $\mathrm{O}_{2}$-balance of Lake Lungern.

The direct measurement of the $\mathrm{CH}_{4}$-flux at the sediment-water-interface and of the $\mathrm{CH}_{4}$-concentrations in sediment cores as well as the determination of the age of methane bubbles lead to the conclusion, that the hypolimnic oxygen depletion is partly due to the oxidation of fossile methane penetrating the lake from below.
\end{abstract}

\section{Einleitung und Problemstellung}

Der Lungernsee (Abb. 1) ist das oberste Glied der im langgezogenen Tal zwischen Brünigpass und Vierwaldstättersee eingebetteten Seenkette. Obwohl er heute als Stausee dient, ist er in seinem heutigen Ausmass glazialen Ursprungs. Nur etwa 20\% des einfliessenden Wassers stammen aus Gebirgsbächen des natürlichen Einzugsgebietes. Im weiteren wurden der Hauptzufluss und der Abfluss nebeneinander in einer Tiefe von etwa $35 \mathrm{~m}$ verlegt. Seit 1934 schwankt der Seespiegel jährlich um etwa $15 \mathrm{~m}$ (677-692 m ü.M.). Bei maximalem Seestand beträgt das Volumen etwa 62 Millionen $\mathrm{m}^{3}$, die Seefläche rund $2 \mathrm{~km}^{2}$ und die Maximaltiefe $72 \mathrm{~m}$. Der tiefste Wasserstand wird jeweils im März und die Pflichtkote von $689 \mathrm{~m}$ ü. M. am 15.Juni erreicht. Während der Zeit von Juni bis Februar betragen die Pegelschwankungen weniger als $2 \mathrm{~m}$. Die jährliche Abflussmenge variiert zwischen 100 und 200 Millionen $\mathrm{m}^{3}$.

Im Längsprofil gliedert sich der See in drei Teile (Abb. 1):

a) der am obern Ende bei Lungern als Flachsee ausgebildete Teil mit Tiefen zwischen 10 und $20 \mathrm{~m}$, liegt im Vorfrühling regelmässig trocken;

b) beim mittleren Teil handelt es sich um ein trogförmiges Becken mit einer maximalen Seetiefe von $70 \mathrm{~m}$;

c) am untern Ende bei Kaiserstuhl befindet sich das vordere Becken mit einer maximalen Seetiefe von $48 \mathrm{~m}$. Hier befinden sich Hauptzufluss und Abfluss. 


\section{LUNGERNSEE}

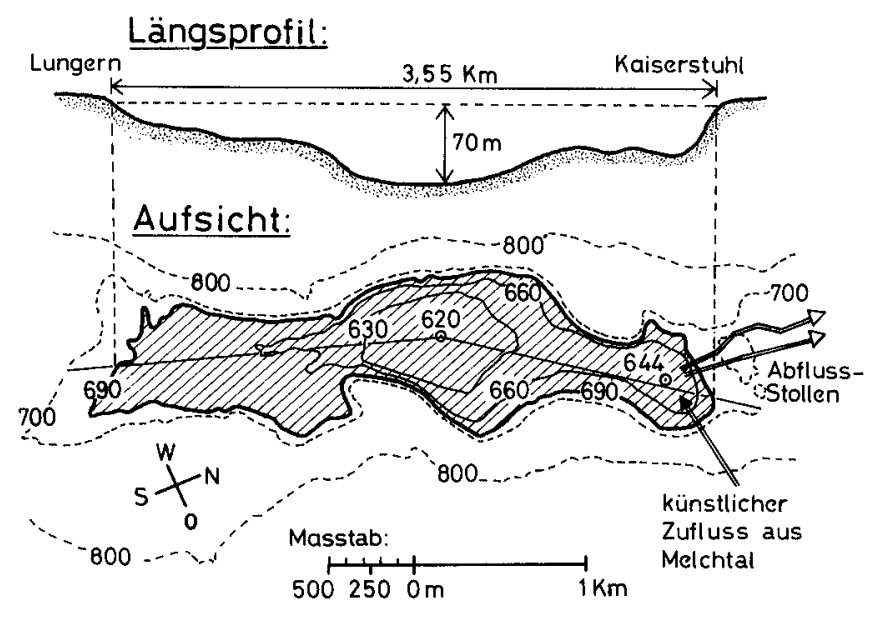

660 Kote in $m$ ü. $M$.

Abb. 1. Die Topographie des Lungernsees. Isohypsen in Metern über Meer.

Figure 1. Topography of Lake Lungern. Isohypses in meters above sealevel. Main inflow and outflow at the northern end of the lake.

Aufgrund monatlicher Untersuchungen im Jahre 1971 lässt sich der allgemeine Charakter des Sees folgendermassen umschreiben [18]:

- Basierend auf den Parametern «Primärproduktion, Sichttiefe und Nährstoffkonzentrationen» ist der See in der Trophieskala als nährstoffarmes oligo- bis mesotrophes Gewässer einzustufen.

- Die beobachtete Anaerobiose im Hypolimnion, verbunden mit Nitratreduktion und erhöhter Phosphorrücklösung aus den Sedimenten während der Stagnationsphase stehen im Widerspruch zum sonst oligo- bis mesotrophen Charakter des Sees.

Im Winter 1973/74 wurde der Wasserspiegel bis auf die Kote von $660 \mathrm{~m}$ ü.M. abgesenkt. Zur Seeoberfläche aufsteigende Gasblasen $\left(93,5 \% \mathrm{CH}_{4}, 2,1 \% \mathrm{~N}_{2}, 4,3 \%\right.$ $\mathrm{O}_{2}$ ) deuteten auf eine intensive Methanproduktion der Sedimente hin.

Diese Arbeit zeigt, dass

- die Oxidation von Methan die Ursache der beobachteten hypolimnischen Anaerobiose ist und

- bei der beobachteten niedrigen Primärproduktion die intensive Methanproduktion mindestens teilweise auf allochthonen Quellen basieren muss.

Die ökologische Bedeutung der Methanoxidation besteht qualitativ darin, dass sie Sauerstoff verbraucht und damit zu einer schnelleren Zehrung der Sauerstoffvorräte im See beiträgt. Hierauf wurde bereits mehrfach von Rossolimo und Kuznecova [42], Ohle [34], Overbeck und Ohle [38] und Naguib [32] hingewiesen. 
Auf die quantitative Bedeutung der mikrobiellen Oxidation von Methan im Hypolimnion eutropher Seen hat Rudd [44, 45, 47, 48] in mehreren Publikationen hingewiesen. Naguib [32] hat gezeigt, dass methanoxidierende Bakterien in der Natur weit verbreitet sind und aus verschiedenen Biotopen, wie z.B. Seewasser, Seesedimenten, Gartenerde und Erdölschlamm, angereichert werden können. Whittenburg et al. [55] haben mehr als 100 obligat aerob wachsende Methanoxidanten identifiziert, Kvasnikov [27] isolierte auch fakultative Methanoxidanten.

Verschiedene Autoren [31, 33, 44] haben gezeigt, dass methanoxidierende Bakterien hauptsächlich in jener Grenzzone des Hypolimnions auftreten, in der gerade noch Sauerstoff, aber bereits auch Methan vorhanden sind.

Rudd [45, 47] hat 1973 erstmals In-situ-Messungen der Methanoxidation mit Radiotracern im Kurzzeitversuch durchgeführt. Er arbeitete dabei in kleinen eutrophen Flachseen, deren mikrobielle Methanproduktion allein durch seeintern produzierte, sedimentierte organische Partikel aufrechterhalten wird.

\section{Methoden}

\subsection{Messung physikalischer, chemischer und biologischer Parameter in Wasserproben}

Die Wasserproben wurden mit einer Van-Dorn-Flasche und einem FriedingerWasserschöpfer entnommen. Die Sauerstoff- und Methanproben wurden blasenfrei in Glasflaschen abgefüllt. Dabei wurde das mehrfache Volumen der Glasflasche mit Probenwasser durchgespült (Abb.2).

Die Temperatur wurde mit dem Oxytester nach Ambühl [2] gemessen, die Sauerstoffkonzentration nach Winkler [56] (Modifikation nach Alsterberg [1]) bestimmt, der $p H$-Wert mit dem pH-Gerät, Typ PHM-24-Radiometer, gemessen, die Methankonzentration mit der Kopfgasmethode gaschromatographisch bestimmt [6].

Zur Altersbestimmung des Methans wurden $301 \mathrm{der}$ im See aufsteigenden Gasblasen mit Hilfe eines Trichters unter Wasser in einen evakuierten Ballon geleitet. Der gefüllte Ballon wurde anschliessend in eine evakuierte Gasflasche entleert. Die

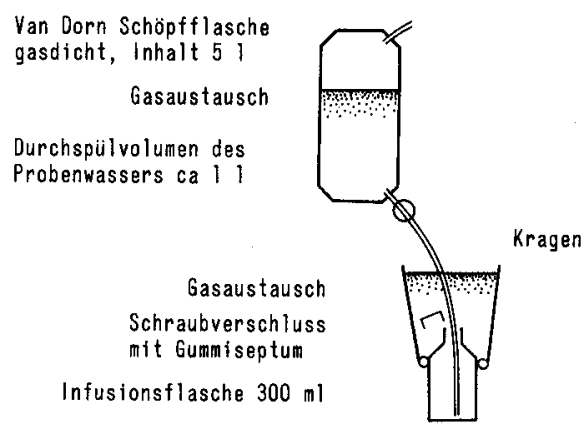

Abb. 2. Probenahme für Methananalysen.

Figure 2. Water sampling for measuring methane concentrations. The water from a Van Dorn sampler is filled into $300 \mathrm{ml}$ infusion flasks by flushing the sampled water several times the volume of the infusion flask. A collar on the flask (Kragen) allows bubble free closing with a rubber septum. 
Altersbestimmungen wurden am Institut für exakte Wissenschaften der Universität Bern mit Hilfe der $\mathrm{C}_{14}$-Radiocarbon-Methode durchgeführt.

Zur Bestimmung der Methanoxidationsrate wurden etwa $150 \mathrm{ml}$ Seewasser blasenfrei in eine kalibrierte Infusionsflasche abgefüllt, mit einem Gummiseptum verschlossen und mit 6,6 $\mu \mathrm{g} \mathrm{C}_{14}-\mathrm{CH}_{4}$ versetzt. Die Proben wurden geschüttelt, bei Insitu-Temperatur in verschlossenen, mit Wasser gefüllten Kühlboxen während 4-7 Stunden inkubiert und anschliessend mit $1 \mathrm{ml} 1 \mathrm{n} \mathrm{NaOH}$ (pH der Probe ca. 12) fixiert [4].

Es wurden die Gesamtaktivität, das metabolisch umgesetzte Methan und das dabei produzierte $\mathrm{CO}_{2}$ gemessen. $\mathrm{Zu}$ diesem Zweck wurden die Proben mit INSTA-GEL ${ }^{\circledR}$ versetzt und deren Aktivität im Liquid-Scintillation-Spektrometer bestimmt.

\subsection{Messung chemischer und biologischer Parameter in Sedimentproben}

Die Sedimentproben wurden mit einem Sedimentbohrlot der Firma Züllig entnommen. Der eigentliche Probensammler bestand aus einem etwa $1 \mathrm{~m}$ langen und $3,3 \mathrm{~cm}$ dicken Plexiglasrohr. Damit konnten bis zu $60 \mathrm{~cm}$ lange Kerne entnommen werden.

Zur Bestimmung der Methankonzentration wurde das Sediment portionenweise mit speziell angefertigten Plexiglaszylindern unter Luftabschluss aus dem Kern vom unteren Ende her entnommen (siehe Abb.3, Schritt 1 und 2). $50 \mathrm{ml}$ der Sediment-

Konstruktion

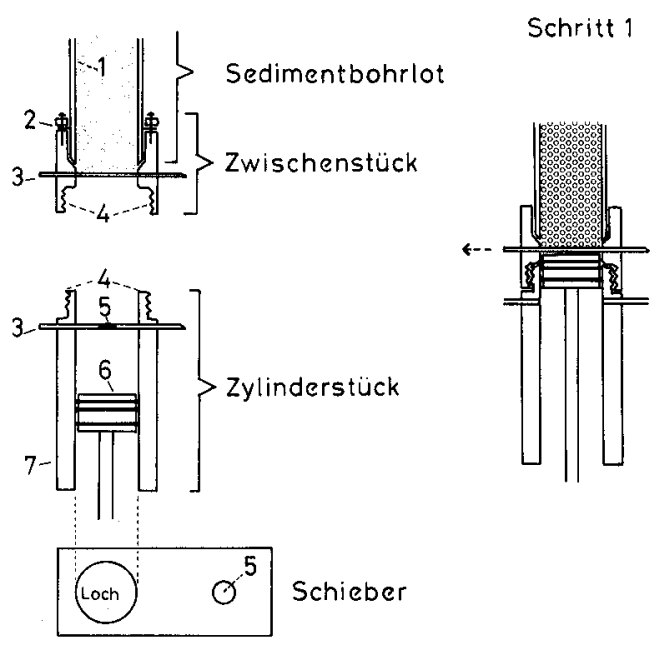

Verarbeitung der Sedimentproben

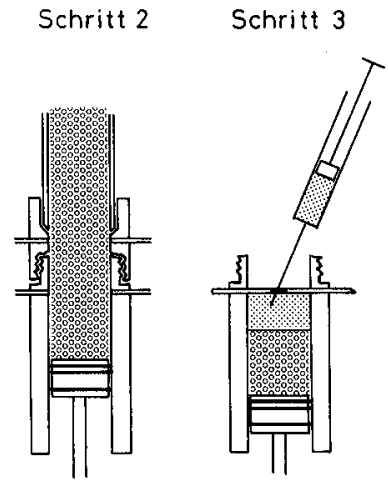

Abb.3. Konstruktion des Probenahmegerätes zur Entnahme von Sediment aus Sedimentbohrloten sowie die Verarbeitung der Sedimentproben für Gasanalysen.

Figure 3. The construction [cylinder (7) with piston (6) and sliding lid (13), connection (2) with sliding lid (3) between cylinder (7) and sediment core sampler (1)] allows the preparation of samples for methane analysis. The sediment sample preparation is shown as step (Schritt) 1, 2 and 3. Step 3: Injection of $20 \mathrm{ml}$ $10 \% \mathrm{NaOH}$ and $20 \mathrm{ml}$ helium to the sediment sample $(50 \mathrm{ml})$ through a rubber septum in the sliding lid. 
probe wurden im luftdichten Plexiglaszylinder mit $20 \mathrm{ml}$ 10prozentiger $\mathrm{NaOH}$ verdünnt und mit $20 \mathrm{ml}$ Helium als Kopfgas überschichtet. Wasser und Helium wurden durch ein Septum, welches sich im Schieber des Zylinderstückes befindet (Abb.3, Schritt 3), injiziert. Dann wurden die Proben ins Lösungsgleichgewicht geschüttelt und die Methankonzentration (in $\mathrm{mg} \mathrm{CH} / 1$ Sedimentschlamm) nach der in Kapitel 2.1 beschriebenen Methode bestimmt, wobei die zusätzliche Verdünnung mit Wasser berücksichtigt wurde.

Zur Bestimmung der Gesamtkonzentration an schwerflüchtigen organischen Kohlenstoffverbindungen (TOC) wurden die Sedimentproben während dreier Tage bei $50{ }^{\circ} \mathrm{C}$ im Wärmeschrank getrocknet und anschliessend zerrieben. Der TOC-Gehalt (in Prozenten des Trockengewichtes) wurde nach Austreiben des anorganischen Kohlenstoffes mit dem CHN-Analyzer (F+M-Modell 185) bestimmt.

Zur Bestimmung der Methanoxidationskapazität in Sedimentkernen wurden die Kerne von oben her schichtweise abgetragen und mit etwas Tiefenwasser verdünnt. Anschliessend wurde das Methan mit $\mathrm{N}_{2}$ ausgetrieben, die einzelnen Portionen mit sauerstoffhaltigem Tiefenwasser versetzt und in Infusionsflaschen blasenfrei abgefüllt. Die so vorbereiteten Proben wurden mit $2 \mathrm{mg} \mathrm{C}$ $_{12}$-Methan $/ 1$ und mit $6,6 \mu \mathrm{g}$ $\mathrm{C}_{14}$-Methan/l versetzt, während der Inkubation von 4 Stunden geschüttelt und nach der oben beschriebenen Methode zur Aktivitätsmessung weiter aufbereitet.

\subsection{Bestimmung der Methandiffusion an der Sedimentoberfläche}

Zur Bestimmung der Methandiffusion durch die Sediment-Wasser-Kontaktschicht wurden Glocken aus verzinktem Blech (Grundfläche $1400 \mathrm{~cm}^{2}$ ) auf die Sedimentoberfläche gesetzt. Eine Glocke war durch zwei PVC-Schläuche mit der Wasseroberfläche verbunden (Abb.4). Durch Ansetzen einer Pumpe konnte der im System eingeschlossene Wasserinhalt umgewälzt und durch Einbringen von konzentrierter $\mathrm{NaOH}$ der pH im System auf 12 erhöht werden. Dadurch wurde jegliche bakterielle Tätigkeit unterbunden.

Zur Bestimmung des Methaneintrags durch die Sedimentoberfläche wurde nach einer Exponierungszeit von 2 bis 3 Wochen der Wasserinhalt des geschlossenen Systems vor der Probenahme durch Zirkulation mittels Schlauchquetschpumpe homogen durchmischt. Zur Probenahme wurde eine mit Wasser gefüllte geschlossene Infusionsflasche mittels zweier Kanülen mit einem der Schläuche verbunden, so dass das umgewälzte Wasser durch die Probenahmeflasche strömen musste (Abb.4). Nach zehnmaliger Erneuerung des Flascheninhaltes wurden die Kanülen entfernt und die Methankonzentration in der Flasche, welche die durchschnittliche Konzentration des gesamten Systems repräsentierte, nach der in Kapitel 2.1 beschriebenen Methode bestimmt. Bei bekanntem Wasserinhalt des geschlossenen Systems (Glokke + Schläuche), bekannter Sedimentoberfläche innerhalb der Glocke und bekannter Expositionsdauer konnte auf diese Weise die durch die Sedimentoberfläche diffundierende Methanmenge pro Zeiteinheit berechnet werden.

An der tiefsten Stelle des mittleren Beckens wurden vier Sedimentkerne zur Bestimmung der Methankonzentrationen entnommen. Ein fünfter Kern wurde zur Bestimmung des Wassergehaltes verwendet. 


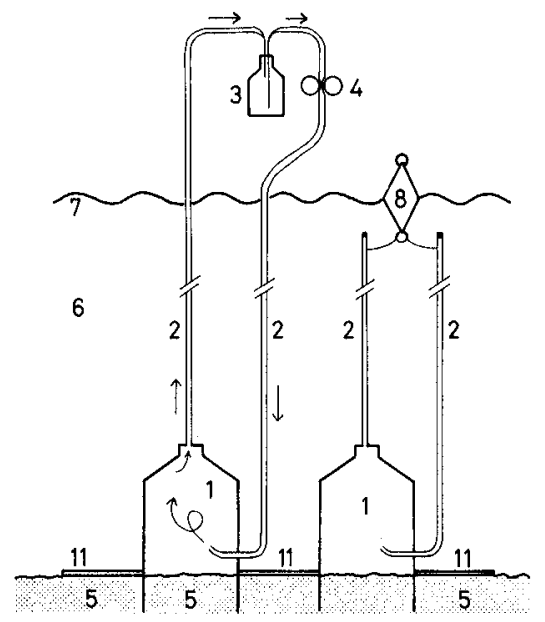

Abb.4. Gerät zur Messung der Diffusion von Methan durch die Sedimentoberftäche.

$1=$ Diffusionsglocken aus Zinkblech, eingelassen in ein Zinkblech (11) vom Ausmass $1 \times 2 \mathrm{~m}$, welches das Einsinken der Glocken verhindert. Inhalt der Glocke: 25 l, Durchmesser: $20 \mathrm{~cm} .2=$ PVC-Schlauch, $8 \mathrm{~mm}$ Innendurchmesser, pro Glocke $2 \times 100 \mathrm{~m}$ Länge, Inhalt $2 \times 5,31.3=$ Infusionsflasche mit Gummiseptum zur Probenahme, Inhalt $300 \mathrm{ml} .4$ = Schlauchquetschpumpe, Förderleistung ca. $400 \mathrm{ml} /$ min. $5=$ Sediment. $6=$ Wasserkörper des Sees, Tiefe ca. $65 \mathrm{~m} .7=$ Wasseroberfläche. $8=$ Boje.

Figure 4. Device for the direct measurement of the methane diffusion through the sediment-water boundary.

$1=$ Diffusion caps made of zinc-sheet fixed in a horizontal zinc plate (11) preventing the caps from sinking into the sediment. Volume of the cap: 251 , diameter: $30 \mathrm{~cm} .2=$ PVC-tube, inner diameter $8 \mathrm{~mm}$, connected with the caps $(2 \times 100 \mathrm{~m}$ length). Volume of the tube: $2 \times 5,31.3=$ Infusion flask with rubber septum, volume $300 \mathrm{ml} .4=$ Peristaltic pump, capacity $400 \mathrm{ml} / \mathrm{min} .5=$ Sediment. $6=$ Water body, depth from surface to ground $65 \mathrm{~m} .7=$ Lake surface. $8=$ Buoy.

The water within the system is fixed with $\mathrm{NaOH}(\mathrm{pH}$ 12) and exposed to methane invasion for several weeks. Before sampling the water is homogeneously mixed within the system by aid of the peristaltic

pump. A representative sample of the methane concentration is obtained in the infusion flask.

Die molekulare Methandiffusion im Sediment wurde aufgrund der Methankonzentrationsgradienten im Sedimentkern berechnet. Unter der Annahme, dass die Methankonzentrationen im Sedimentkern im Steady state seien, wurde die Grössenordnung der Methandiffusion (F) durch die Sedimentoberfläche mit Hilfe der Diffusionsgleichung

$$
\mathrm{F}=\Phi \mathrm{D}_{\mathrm{s}} \frac{\mathrm{dC}}{\mathrm{dz}}
$$

abgeschätzt, wobei nach Untersuchungen von Imboden [24] folgende Grössen eingesetzt wurden:

$\mathrm{D}_{\mathrm{s}}=$ Diffusionskoeffizient im Interstitialwasser bei $5^{\circ} \mathrm{C}=1,5 \times 10^{-5} \mathrm{~cm}^{2} / \mathrm{sec}$.

$\Phi=$ Porosität als Anteil des Porenvolumens am Gesamtvolumen des Sedimentes $=0,95 \mathrm{~cm}^{3} / \mathrm{cm}^{3}$.

$\mathrm{dc} / \mathrm{dz}=$ Konzentrationsgradient des im Porenwasser gelösten Methans ([mg/ $\left.\mathrm{cm}^{3}\right] \cdot \mathrm{cm}^{-1}$; berechnet aus den Methankonzentrationen in den Sedimentkernen. $\mathrm{F}=$ Methanflux in $\mathrm{mg} / \mathrm{cm}^{2} \cdot \mathrm{sec}$. 


\subsection{Bestimmung des Eddydiffusionskoeffizienten im Hypolimnion}

Während der Aufwärmephase wurden vertikale Eddydiffusionskoeffizienten $\left(\mathrm{K}_{\mathrm{z}}\right)$ nach der von $\mathrm{Li}$ [29], Imboden und Emerson [25] und Wirz [57] angewandten Methode aus dem zeitlichen und örtlichen Temperaturgradienten berechnet.

$$
K(T, z)=-\frac{\int_{z}^{z_{\max }} \frac{\partial T}{\partial t} \cdot A(z) d z}{\frac{\partial T}{\partial z} \cdot A(z)}
$$

für $\mathrm{T}=$ Temperatur, $\mathrm{t}=$ Zeit, $\mathrm{A}=$ Isobathenfläche, $\mathrm{z}=$ Tiefe.

\subsection{Berechnung der Stoffmengen im See}

Als Grundlagen für die Berechnung des Seeinhaltes dienten die Isobathenflächen, welche aus der topographischen Karte des Lungernseegebietes der Centralschweizerischen Kraftwerke, Maßstab 1:5000 (angefertigt 1921-1930), berechnet wurden.

Für die Volumenberechnung wurde das Hypolimnion in Pyramidenstümpfe unterteilt, mit den planimetrierten Isobathenflächen als Grund- und Deckfläche (Abb. 5).

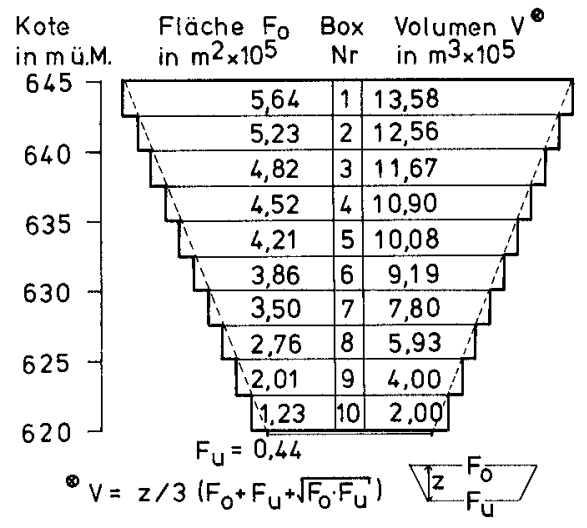

Abb.5. Kompartimentierung des Hypolimnions im mittleren Becken des Lungernsees.

Figure 5. Hypolimnion compartments in the central basin of Lake Lungern used in the mathematical model and for balancing dissolved substances. $F_{0}=$ upper area of the boxes. $F_{u}=$ lower area of box

No. $10 . \mathrm{V}=$ volume of the boxes. Left-hand scale: altitude in meters above sealevel.

\section{Resultate}

\subsection{Temperatur und Eddydiffusion}

Die Isothermendarstellung (Abb.6) zeigt, dass das mittlere Becken des Lungernsees holo-monomiktisch ist. Die Vollzirkulation dauert von Januar bis März. Abb. 7 zeigt den Temperaturgang während der Stagnation in einzelnen Tiefenstufen des Hypolimnions. Hieraus ist ersichtlich, dass sich die Schichten mit weniger als $17,5 \mathrm{~m}$ 
Abstand vom Seegrund der tiefsten Stelle nur schwach erwärmen und sich im Juni/ Juli 1975 vorübergehend gar leicht abkühlten. In Schichten, die höher als $22 \mathrm{~m}$ über Grund liegen, wird das Wasser vom Mai bis zum Oktober stetig aufgewärmt.

Kote in $m$ ü. $M$.

Hypolimnion

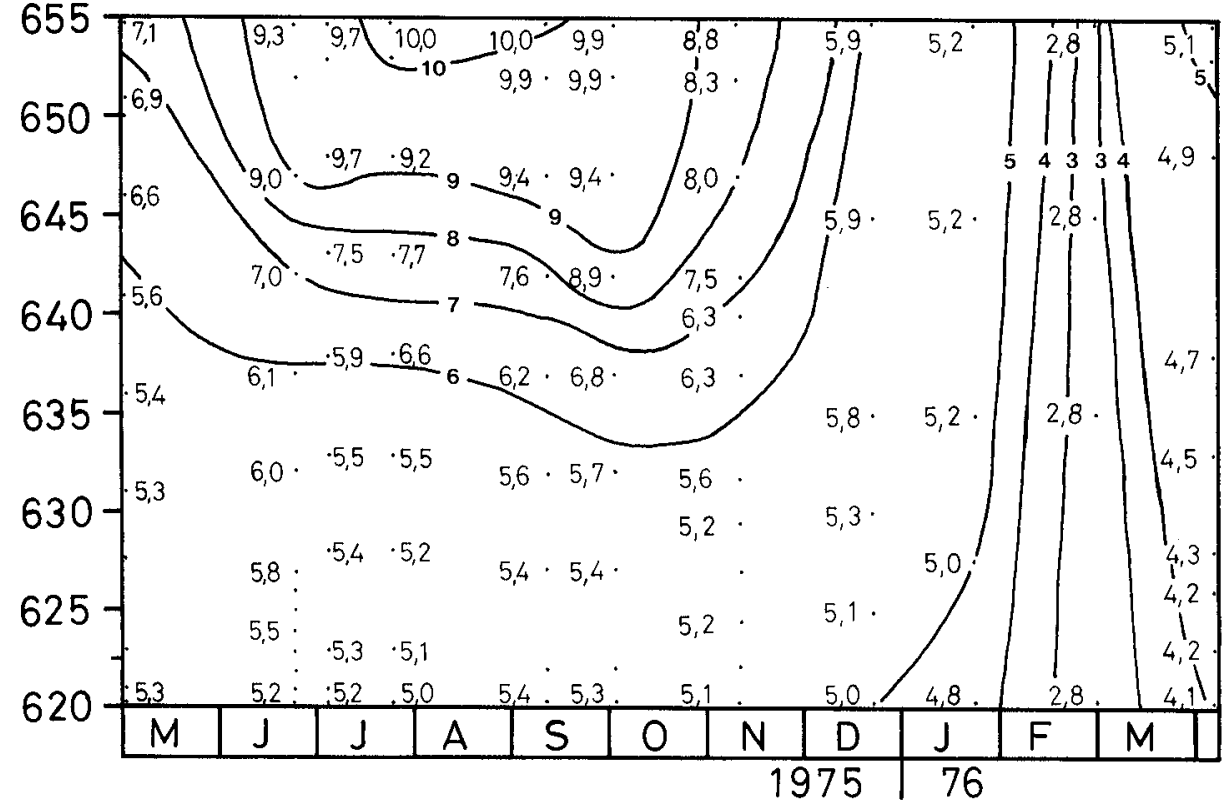

Abb.6. Isothermen im mittleren Becken des Lungernsees, 1975/76. Temperatur in ${ }^{\circ} \mathrm{C}$. Die Kote in $655 \mathrm{~m}$ ü. M. befindet sich etwa $35 \mathrm{~m}$ unter der Seeoberfläche.

Figure 6. Temperature-isopleths in the central basin of Lake Lungern, 1975/76. Temperature in ${ }^{\circ} \mathrm{C}$. The upper boundary of the compartment in $655 \mathrm{~m}$ above sealevel is approximately $35 \mathrm{~m}$ below the lake surface. Full overturn in February and March. Stratification from April to December in the upper and from April to February in the deep hypolimnion.

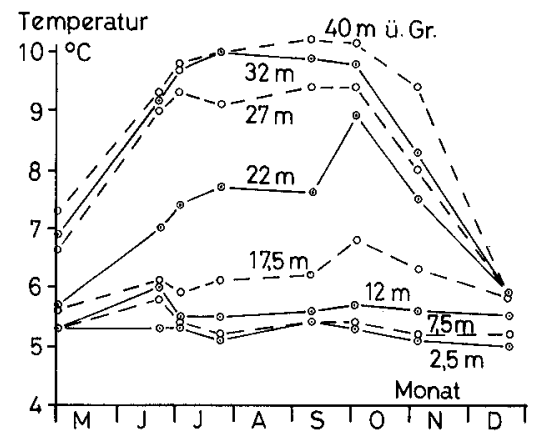

Abb. 7. Zeitlicher Temperaturverlauf in verschiedenen Tiefen des mittleren Lungernseebeckens 1975.

Dauer der Erwärmungsphase bis Oktober.

Figure 7. Temporal development of the temperature in different depths of the central basin of Lake Lungern 1975. The warming period lasts until October. 
Für die Isobathenfläche in $645 \mathrm{~m}$ über Meer $(=25 \mathrm{~m}$ ü. Gr.) wurden die in Tabelle 1 zusammengestellten vertikalen Eddydiffusionskoeffizienten $\left(\mathrm{K}_{\mathrm{z}}\right)$ bestimmt. In Schichten unterhalb von $645 \mathrm{~m}$ ü. M. sind die zeitlichen und örtlichen Temperaturschwankungen teilweise kleiner als $0,2^{\circ} \mathrm{C}$ /Monat und liegen im Streuungsbereich der Temperatursonde.

\subsection{Sauerstoff}

Die jahreszeitliche Veränderung der Sauerstoffkonzentration an der tiefsten Stelle des mittleren Beckens ist in Abb. 8 dargestellt. Mit dem Entstehen einer ersten

Tabelle 1. Lungernsee, mittleres Becken, 1975. Eddydiffusionskoeffizienten in $645 \mathrm{~m}$ ü. M.

Table 1. Lake Lungern, central basin, 1975. Eddy diffusion coefficients $\left(\mathrm{K}_{\mathrm{z}}\right)$ in $645 \mathrm{~m}$ above sealevel.

\begin{tabular}{lc}
\hline Zeitintervall/Time interval & $\mathrm{K}_{\mathrm{z}}$ in $\mathrm{cm}^{2} / \mathrm{sec}$ \\
\hline $30.4 .-23.6$. & 0,1 \\
$23.6 .-3.7$. & 0,1 \\
$3.7-24.7$. & 0,05 \\
$24.7 .-10.9$. & $<0,05$ \\
$10.9 .-2.10$. & 0,2 \\
\hline
\end{tabular}

Kote in $m$ ü. $M$.

Hypolimnion

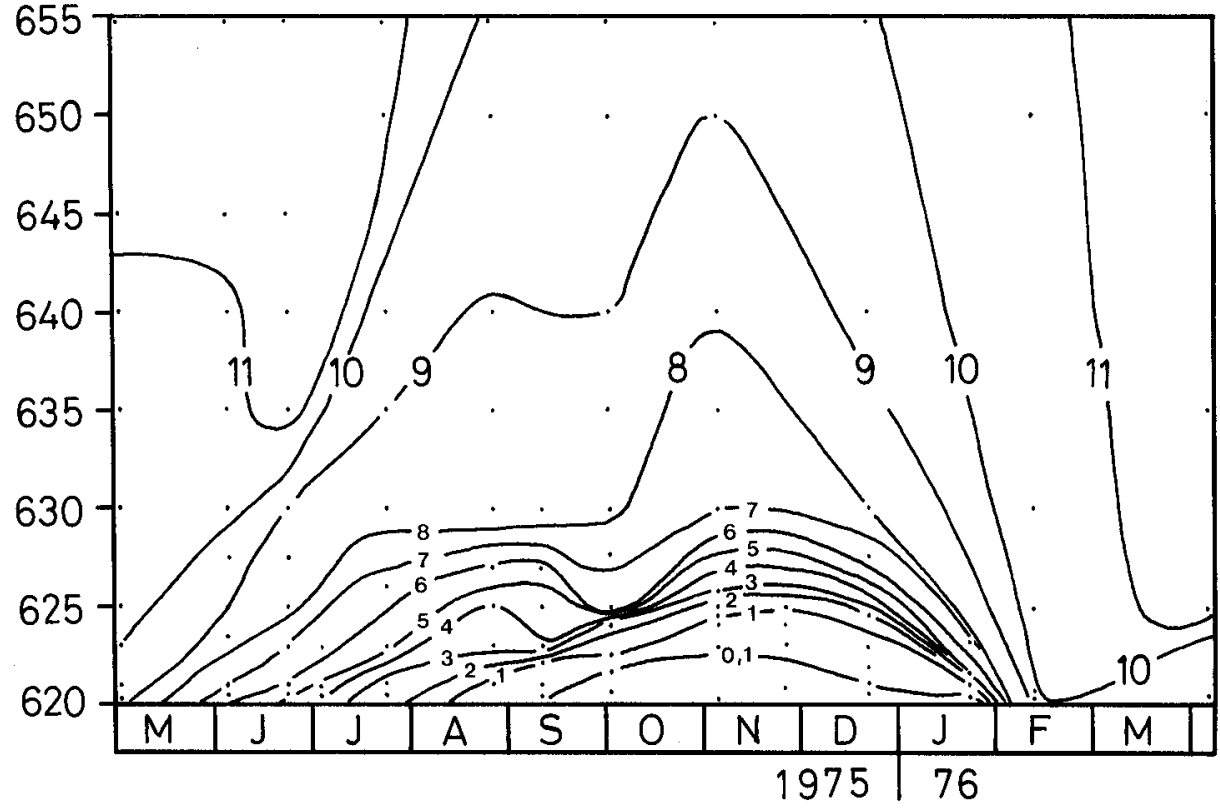

Abb. 8. Sauerstoffisopleten im mittleren Becken des Lungernsees, 1975/76. $\mathrm{O}_{2}$-Konzentration in $\mathrm{mg} / 1$. Figure 8. $\mathrm{O}_{2}$-isopleths in the central basin of Lake Lungern, 1975/76. $\mathrm{O}_{2}$-concentrations in mg/l. Fast $\mathrm{O}_{2}$ consumption above the sediment leads to an $\mathrm{O}_{2}$-depletion from September to January. The high $\mathrm{O}_{2}$ consumption is restricted to the zone between 620 and $630 \mathrm{~m}$ above sealevel. $\mathrm{O}_{2}$-saturation in all depths 
Temperaturschichtung im Mai setzt bereits eine massive Sauerstoffzehrung in den sedimentnahen Schichten ein, welche sukzessive die unteren Schichten des Hypolimnions erfasst, sich jedoch während der ganzen Stagnationsphase auf die untersten $15 \mathrm{~m}$ beschränkt. Trotz der im November einsetzenden Teilzirkulation bleibt die sedimentnahe Schicht bis Ende Januar sauerstoffarm.

Über die horizontale Verteilung der Sauerstoffkonzentrationen während der Sommerstagnation (Juli und September 1974) gibt Abb.9 Auskunft. Es geht daraus hervor, dass sich die intensive Sauerstoffzehrung auf das mittlere Seebecken beschränkt, und es fällt auf, dass die Sauerstoffisopleten nicht parallel zu der Sedimentoberfläche, sondern horizontal verlaufen. An der tiefsten Stelle ist auch am wenigsten Sauerstoff vorhanden, wobei aber die sedimentnahen Wasserschichten der beiden Randbecken, dem oligo- bis mesotrophen Charakter des Sees entsprechend, während des ganzen Jahres mehr als $8 \mathrm{mg} \mathrm{O} / 1$ aufweisen. Die ausgesprochene Homogenität der Sauerstoffkonzentration in horizontaler Richtung deutet auf eine gute horizontale Durchmischung des Wassers hin.

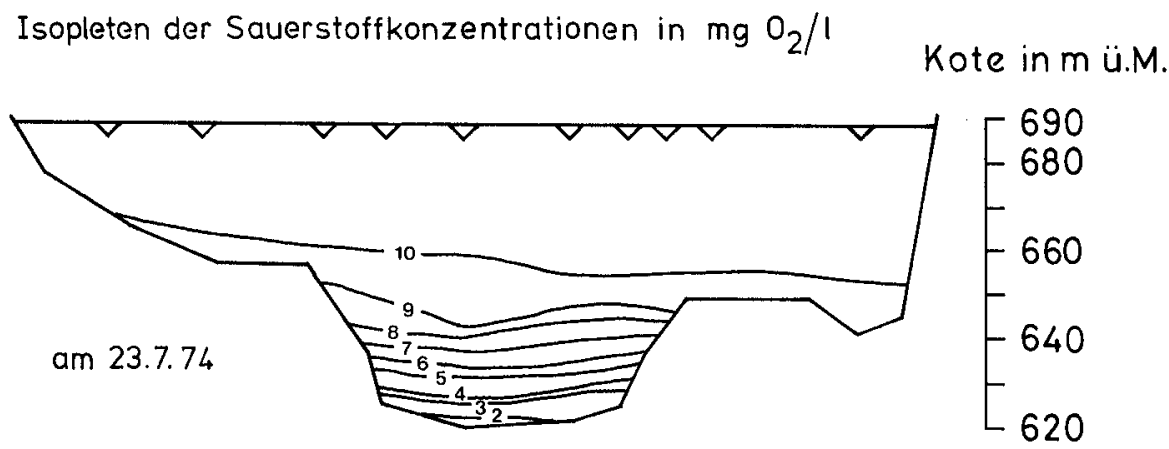

$\begin{array}{ccc}\text { hinteres } & \text { mittleres } & \text { vorderes } \\ \text { Lungern } & \text { Becken } & \text { Kaiserstuhl }\end{array}$

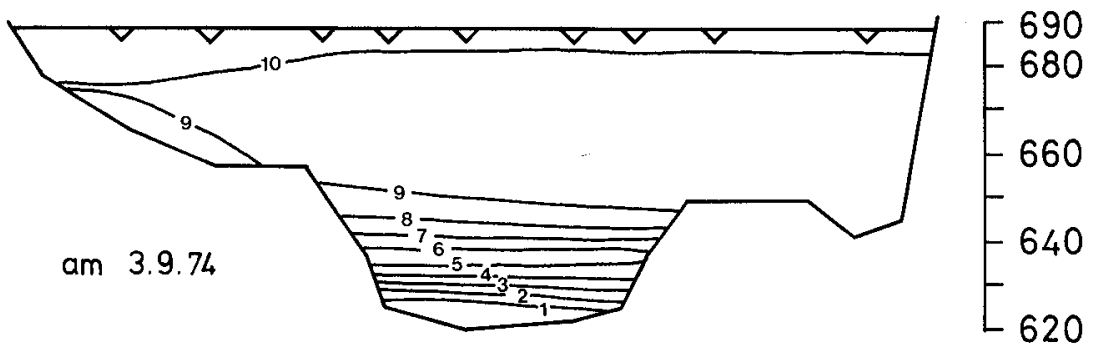

Abb. 9. Horizontale und vertikale Verteilung der Sauerstoffkonzentrationen in $\mathrm{mg} / \mathrm{l}$ im Lungernsee am

23. Juli und am 3. September 1974. Die an der Oberfläche eingezeichneten Dreiecke markieren die Probenahmestellen.

Figure 9. Horizontal and vertical distribution of $\mathrm{O}_{2}$ in $\mathrm{mg} / \mathrm{l}$ in the three basins of Lake Lungern on 23 July and 3 September 1974. Sampling sites are marked by triangles at the lake surface. Right-hand scale: altitude in meters above sealevel. Left side: southern end (Lungern), right side: northern end (Kaiserstuhl). Oxygen depletion was observed only in the central basin. 


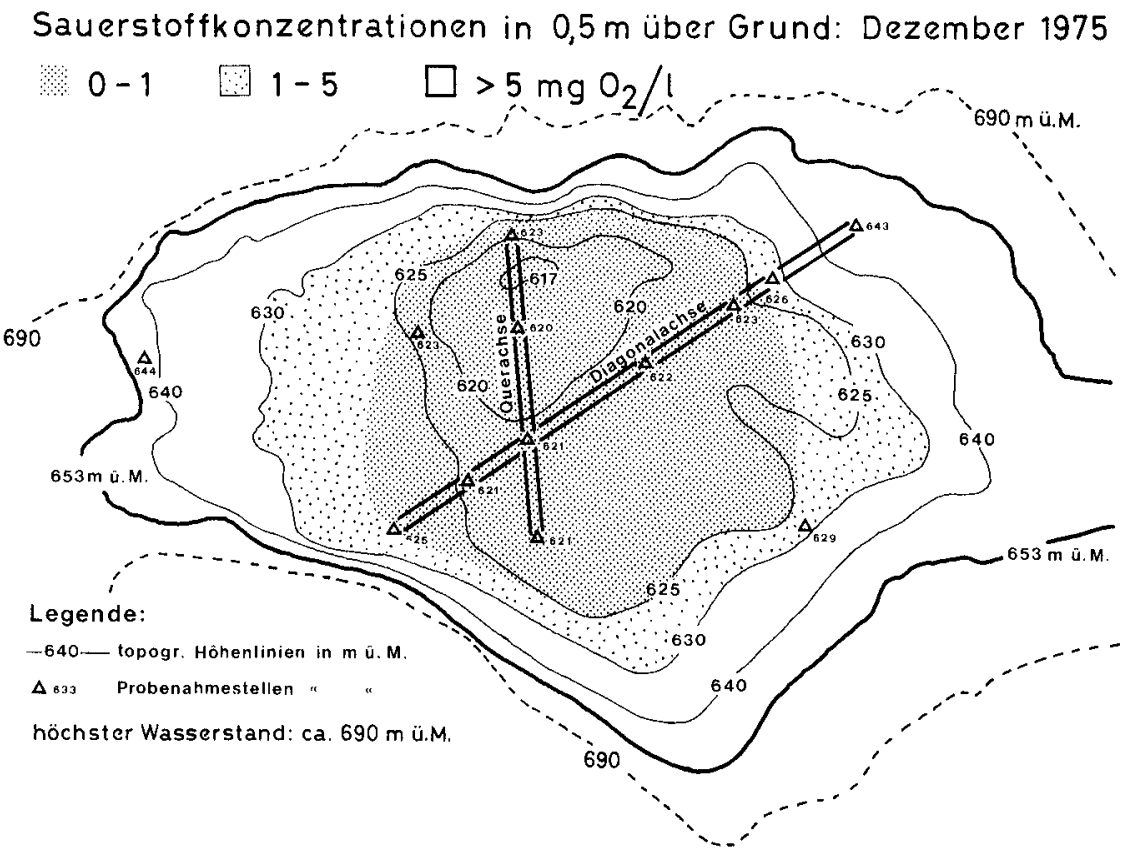

Abb. 10. Horizontale Verteilung der Sauerstoffkonzentrationen über dem Grund des mittleren Lungernseebeckens, Ende Stagnation 1975.

Figure 10. Horizontal distribution of $\mathrm{O}_{2}$-concentrations $0.5 \mathrm{~m}$ above the sediment of the central basin of

Lake Lungern at the end of the stagnation period 1975. The triangles mark the sampling sites, the accompanying numbers represent the altitude of the sediment in meters above sealevel. $\mathrm{O}_{2}$-depletion $\left(\mathrm{O}_{2}\right.$ concentration $<1 \mathrm{mg} / \mathrm{l}$ ) covers an area of approximately $200,000 \mathrm{~m}^{2}$.

Detailliertere Information über die horizontale Verteilung des Sauerstoffes in den untersten $5 \mathrm{~m}$ des Hypolimnions im mittleren Becken kann aus den Abb. 10 und 11, die auf einer Untersuchung im Dezember 1975 basieren, entnommen werden. Abb. 10 zeigt die Sauerstoffkonzentrationen in $50 \mathrm{~cm}$ über Grund. Abb. 11 gibt die Sauerstoffkonzentrationen in einem Quer- und einem Diagonalschnitt des Seebekkens wieder. Die einzelnen Probenahmestellen sind in Abb. 10 bezeichnet. Daraus ist ersichtlich, dass ein Gebiet von etwa $200000 \mathrm{~m}^{2}$ Sedimentoberfläche im Verlaufe der Stagnation anaerob oder zumindest sauerstoffarm $\left(<1 \mathrm{mg} \mathrm{O}_{2} / 1\right)$ wird. Im wesentlichen bestätigen diese Untersuchungen die Resultate der Untersuchungen aus dem Jahr 1974, was die horizontale Lage der Sauerstoffisopleten anbelangt, wobei allerdings festzustellen ist, dass unmittelbar über dem Grund örtlich begrenzte Unregelmässigkeiten auftreten können.

Aufgrund der gemessenen Sauerstoffprofile wurde für einzelne Kompartimente des Hypolimnions die Sauerstoffnettozehrung zwischen zwei Probenahmen berechnet (Tab.2). Als Nettozehrung wird die zeitliche Veränderung der Sauerstoffmenge in einem Kompartiment definiert, welche aus den antagonistisch wirkenden Grössen «Sauerstoffeintrag» und «Sauerstoffverbrauch» resultiert. Die negativen Zehrungsraten im Juni und September zeigen an, dass in diesen Zeitabschnitten die Sauer- 


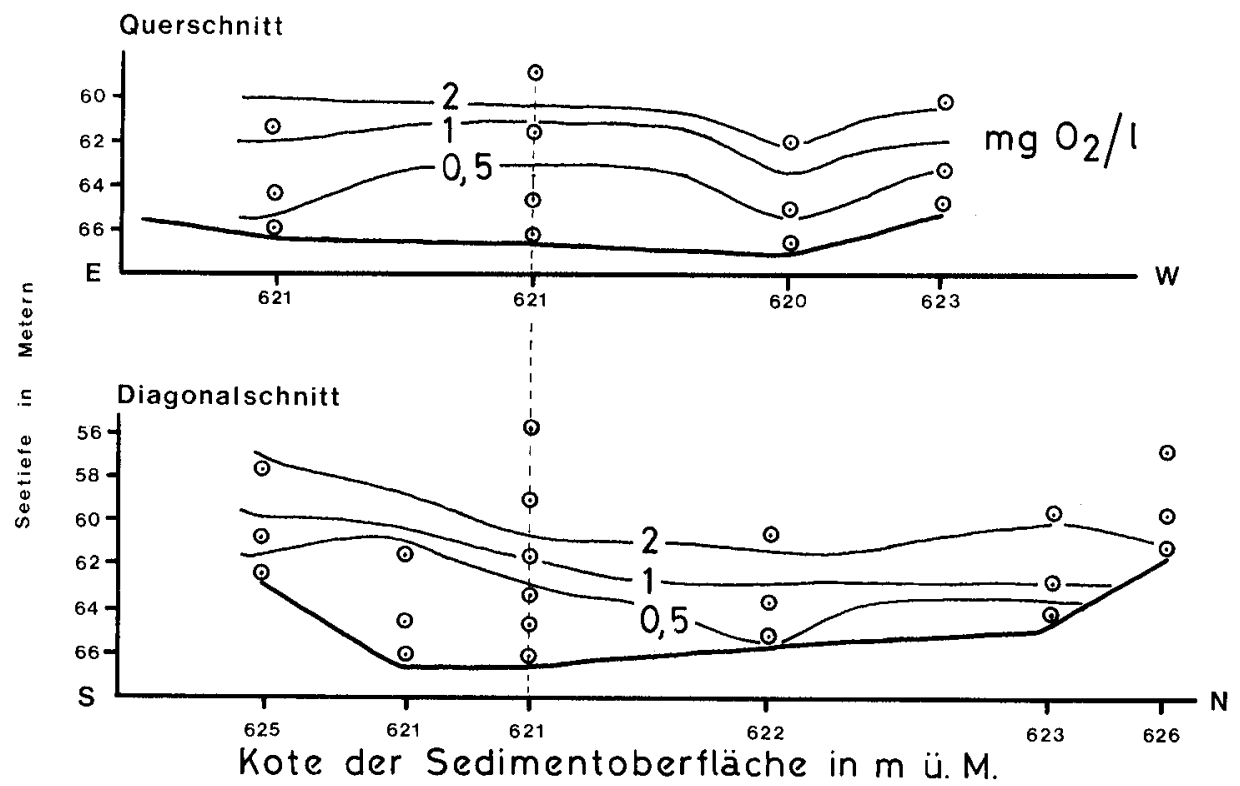

Abb. 11. Sauerstoffkonzentrationen im Quer- und Diagonalschnitt über dem Grund des mittleren

Lungernseebeckens im Dezember 1975. Die Schnittachsen sind in Abb. 10 eingezeichnet.

Figure 11. $\mathrm{O}_{2}$-concentrations in the central basin of Lake Lungern in December 1975. Upper part: crosssection (Querschnitt), lower part: diagonal section of the basin (the axes are marked in fig. 10). Left-hand scale: altitude above sealevel.

Tabelle 2. $\mathrm{O}_{2}$-Nettozehrung im Hypolimnion des mittleren Beckens, 1975. $\mathrm{O}_{2}$-Nettozehrungsraten pro Kompartiment in Mol/Tag.

Table 2. $\mathrm{O}_{2}$-net consumption in the hypolimnion of the central basin of Lake Lungern, 1975. $\mathrm{O}_{2}$-net consumption rates per box in mole/day.

\begin{tabular}{|c|c|c|c|c|c|c|}
\hline \multirow[t]{2}{*}{$\begin{array}{l}\text { Zeitintervall } \\
\text { Time interval }\end{array}$} & \multicolumn{6}{|c|}{$\begin{array}{l}\text { Kompartimente in Metern über Meer } \\
\text { Boxes in meters above sealevel }\end{array}$} \\
\hline & $620-625$ & $625-630$ & $630-635$ & $635-640$ & $640-645$ & $620-645$ \\
\hline 30.4.-5.6. & 519 & 519 & 258 & 486 & 13 & 1753 \\
\hline 6.6.-23.6. & 1739 & 706 & -1156 & -6444 & -3311 & -1738 \\
\hline 23.6.-24.7. & 1219 & 2922 & 2987 & 5901 & -4429 & 13574 \\
\hline 24.7.-26.8. & 924 & 1218 & 927 & 1597 & 2176 & 9822 \\
\hline 26.8.-2.10. & 338 & -1278 & 19 & -470 & 5 & -1429 \\
\hline $2.10 .-5.11$ & 926 & 3653 & 2312 & 2370 & 1735 & 11000 \\
\hline 5.11.-19.12. & -152 & -1454 & -1840 & -2409 & -2159 & -8045 \\
\hline \multirow{2}{*}{\multicolumn{7}{|c|}{$\mathrm{O}_{2}$-Mengen pro Kompartiment in $\mathrm{Mol} \times 10^{3}$ : }} \\
\hline \multicolumn{4}{|c|}{$\mathrm{O}_{2}$-amounts per box in mole $\times 10^{3}:$} & & & \\
\hline am 30.4 & 170 & 437 & 614 & 740 & 894 & 2856 \\
\hline am 2.10 & 40 & 322 & 503 & 621 & 745 & 2231 \\
\hline am 5.11 . & 8 & 198 & 424 & 540 & 686 & 1856 \\
\hline \multicolumn{7}{|c|}{$\begin{array}{l}\text { Sauerstoffverluste in } \mathrm{Mol} \times 10^{3} \text { : } \\
\mathrm{O}_{2} \text {-losses in mole } \times 10^{3}:\end{array}$} \\
\hline vom 30.4.-2.10. & 130 & 115 & 111 & 119 & 149 & 625 \\
\hline vom 30.4.-5.11. & 162 & 239 & 190 & 200 & 208 & 1000 \\
\hline
\end{tabular}




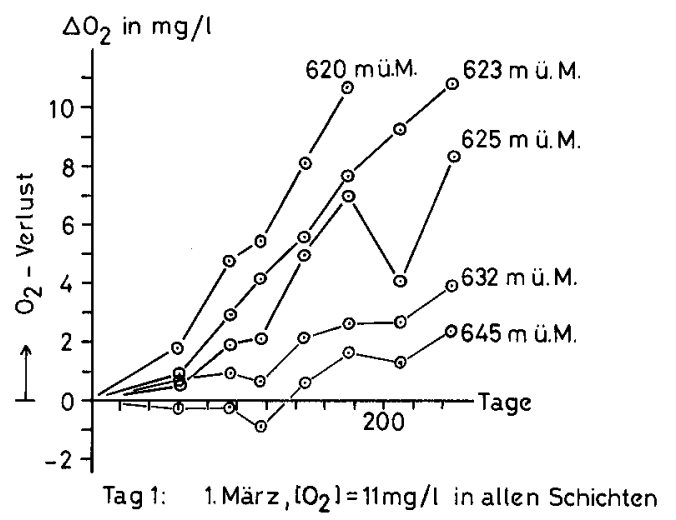

Abb. 12. Sauerstoffverluste im mittleren Becken des Lungernsees in einzelnen Tiefen während der Stagnation vom 1. März bis 5. November 1975.

Figure 12. Net- $\mathrm{O}_{2}$-consumption in different depths of the hypolimnion in the central basin of Lake Lungern from 1 March to 5 November 1975. $\mathrm{m}$ ü. M. = means altitude above sealevel. The $\mathrm{O}_{2}$ consumption in 620 and $623 \mathrm{~m}$ above sealevel are almost constant with time. The starting $\mathrm{O}_{2}$ concentration on $1 \mathrm{March}$ was $11 \mathrm{mg} / \mathrm{l}$ in all depths.

stoffzufuhr die Sauerstoffzehrung übertroffen haben muss. Innerhalb der 190tägigen Periode vom 30. April bis 5. November 1975 wurde rund ein Drittel des Sauerstoffanfangsgehaltes im bilanzierten Hypolimnionkompartiment (620-645 m ü.M.) netto gezehrt.

In Abb.12 sind die Sauerstoffverluste einzelner Tiefenstufen im Verlaufe der Stagnation in $\mathrm{mg} \mathrm{O}_{2} / 1$ aufgetragen. Aus dem Kurvenverlauf ist ersichtlich, dass die Sauerstoffzehrung in den untersten $3 \mathrm{~m}$ über dem Grund der Probenahmestelle in der Periode vom 3.April bis 26. August zeitkonstant gewesen ist (Kurve $623 \mathrm{~m}$ ü.M.), dass die Sauerstoffzehrung in den darüberliegenden Tiefenstufen jedoch einige zeitliche Unregelmässigkeiten aufweist.

Der Sauerstoffeintrag durch die Isobathenfläche in $645 \mathrm{~m}$ ü. M. in das darunterliegende Hypolimnion wurde mit Hilfe der Sauerstoffgradienten zwischen 640 und $650 \mathrm{~m}$ ü. M. und der aus den Temperaturdaten berechneten Eddydiffusionskoeffizienten (Kap.2.4) abgeschätzt und ist in Tabelle 3 aufgeführt. In der Periode vom 30. April bis 2. Oktober 1975 wurden durch die Isobathenfläche in $645 \mathrm{~m}$ ü. M. $1,6 \times 10^{5} \mathrm{Mol}$ Sauerstoff in das unterste Hypolimnionkompartiment eingetragen. In der gleichen Zeit betrug die Sauerstoffnettozehrung in diesem Kompartiment $6,3 \times 10^{5} \mathrm{Mol}$ (Tab.2). Daraus ist ersichtlich, dass der vertikale Sauerstoffeintrag durch Eddydiffusion im Sauerstoffhaushalt des unteren Hypolimnions eine untergeordnete, aber nicht unbedeutende Rolle spielt.

\subsection{Methan im Wasserkörper}

Die jahreszeitlichen Veränderungen der Methankonzentration an der tiefsten Stelle des mittleren Beckens sind in Abb.13 dargestellt: Methan ist in Spuren $(<1 \mu \mathrm{g}$ $\mathrm{CH}_{4} / \mathrm{l}$ ) während des ganzen Jahres zu finden. Im August wurden über dem Grund 
Tabelle 3. Sauerstoffeintrag duch die Isobathenfläche in $645 \mathrm{~m} \ddot{u}$. M.

Table 3. $\mathrm{O}_{2}$-input through the upper boundary of the hypolimnion compartment in $645 \mathrm{~m}$ above sealevel.

\begin{tabular}{|c|c|c|c|c|}
\hline $\begin{array}{l}\text { Zeitintervall } \\
\text { Time interval }\end{array}$ & $\begin{array}{l}\mathrm{O}_{2} \text {-Gradient } \\
\text { in } \\
\mathrm{mMol} / \mathrm{cm}^{4} \\
\mathrm{O}_{2} \text {-Gradient } \\
\text { in } \\
\mathrm{mmole} / \mathrm{cm}^{4}\end{array}$ & $\begin{array}{l}\mathrm{K}_{\mathrm{z}} \text { in } \\
\mathrm{cm}^{2} / \mathrm{sec}\end{array}$ & $\begin{array}{l}\mathrm{O}_{2} \text {-Flux } \\
\text { in } \\
\mathrm{mMol} / \mathrm{m}^{2} \cdot \text { Tag } \\
\mathrm{O}_{2} \text {-flux } \\
\text { in } \\
\mathrm{mmole} / \mathrm{m}^{2} \cdot \mathrm{d} \\
\end{array}$ & $\begin{array}{r}\mathrm{O}_{2} \text {-Eintrag } \\
\text { in } \\
\text { Mol/Periode } \\
\mathrm{O}_{2} \text {-input } \\
\text { in } \\
\text { mole/interval } \\
\end{array}$ \\
\hline 30.4.-5.6. & 3,13 & 0,1 & 3,1 & $6,3 \times 10^{4}$ \\
\hline 5.6.-23.6. & 4,07 & 0,1 & 1,8 & $1,8 \times 10^{4}$ \\
\hline 23.6.-24.7. & 0 & $0,07 *$ & 0,7 & $1,3 \times 10^{4}$ \\
\hline 24.7.-26.8. & 5,01 & $0,0^{*}$ & 0 & 0 \\
\hline 26.8.-2.10. & 2,82 & $0,17 *$ & 3,2 & $6,7 \times 10^{4}$ \\
\hline $2.10 .-5.11$ & 1,57 & - & - & - \\
\hline 30.4.-2.10. & & & & $1,6 \times 10^{5}$ \\
\hline
\end{tabular}

${ }^{*} \mathrm{~K}_{\mathrm{z}}=$ Mittelwerte, berechnet aus Tabelle 1/Mean values, calculated from table 1 .

Die $\mathrm{O}_{2}$-Gradienten gelten für den Anfang des Zeitintervalles.

The $\mathrm{O}_{2}$-gradients hold for the beginning of the time intervals.

Kote in $m$ ü. M.

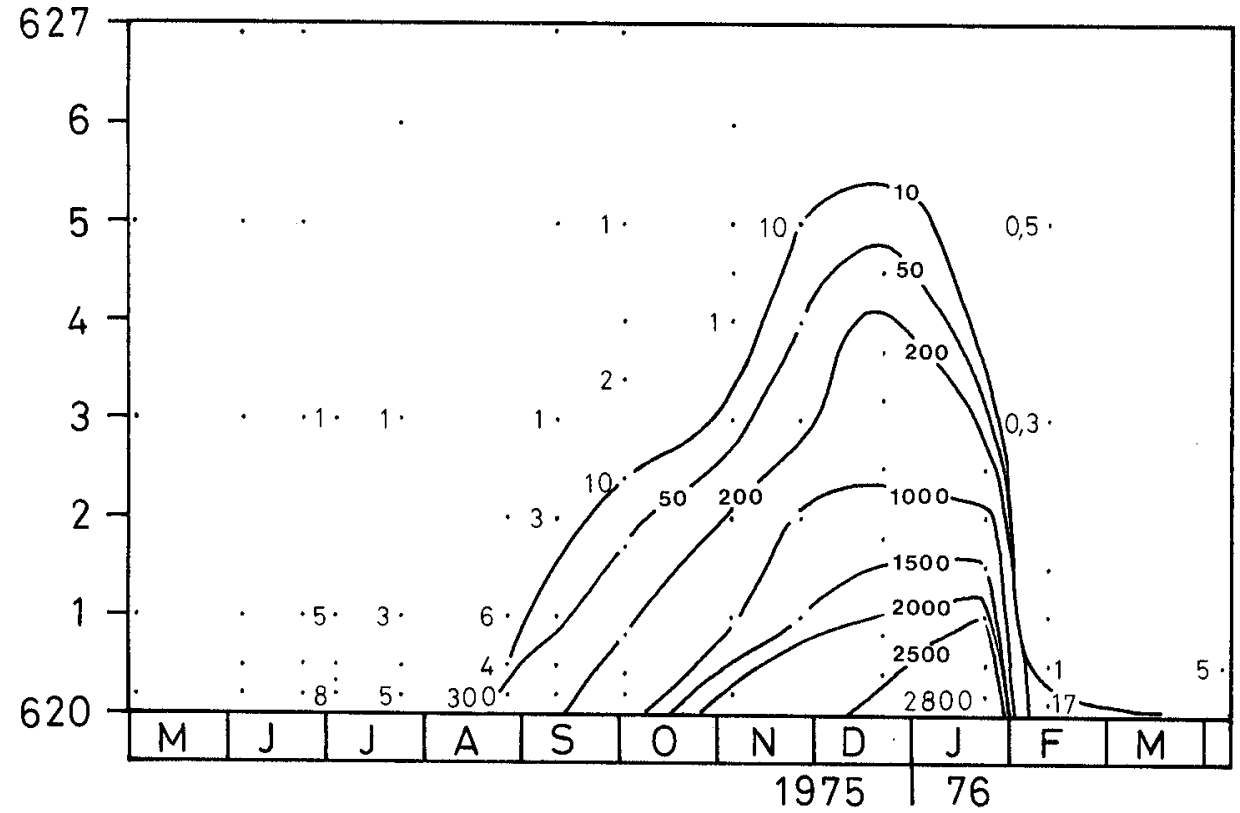

Abb. 13. Methanisopleten im tiefen Hypolimnion des mittleren Lungernseebeckens $1975 / 76 . \mathrm{CH}_{4^{-}}$ Konzentrationen in $\mu \mathrm{g} / 1$.

Figure 13. Methane isopleths in the deep hypolimnion of the central basin of Lake Lungern 1975/76. $\mathrm{CH}_{4}$-concentrations in $\mu \mathrm{g} / 1$. Left-hand scale: altitude above sealevel. 
erstmals Konzentrationen von mehr als $10 \mu \mathrm{g} / 1$ beobachtet. Im weiteren Verlauf der Stagnation nimmt die $\mathrm{CH}_{4}$-Konzentration in den untersten $5 \mathrm{~m}$ stetig zu und erreicht im Januar über Grund Höchstwerte von etwa $3 \mathrm{mg} / \mathrm{l}$, um Anfang Februar wieder bis auf Spuren zu verschwinden.

Im Oktober 1974 wurden in den drei Becken jeweils an der tiefsten Stelle $20 \mathrm{~cm}$ über dem Grund die Methankonzentrationen bestimmt. Im vorderen Becken bei Kaiserstuhl konnte Methan nur in Spuren, im mittleren Becken in Konzentrationen von $800 \mu \mathrm{g} \mathrm{CH}_{4} / 1$ festgestellt werden. Im hinteren Becken bei Lungern betrug die Konzentration über dem Seegrund weniger als $10 \mu \mathrm{g} / \mathrm{l}$. Aufgrund dieser Beobachtungen beschränkt sich die Methanakkumulation im wesentlichen auf das mittlere Becken.

Im Dezember 1975, kurz vor Ende der Stagnation, wurde die horizontale Verteilung des Methans in den untersten $5 \mathrm{~m}$ des mittleren Beckens näher untersucht. Abb. 14 zeigt die horizontale Verteilung der Methankonzentration $0,5 \mathrm{~m}$ über Grund. Abb. 15 gibt die Verteilung der Methankonzentration in einem Quer- und einem Diagonalschnitt des Seebeckens wieder. Die einzelnen Probenahmestellen sind in Abb. 14 eingezeichnet. Ein Vergleich mit Abb. 10 zeigt, dass Methankonzentrationen von mehr als $0,1 \mathrm{mg} / \mathrm{l}$ nur dort auftreten, wo die Sauerstoffkonzentrationen unterhalb von $1 \mathrm{mg} / 1$ liegen. Die Methanisopleten verlaufen, abgesehen von vereinzelten lokalen Störungen, in Übereinstimmung mit den Sauerstoffisopleten horizontal.

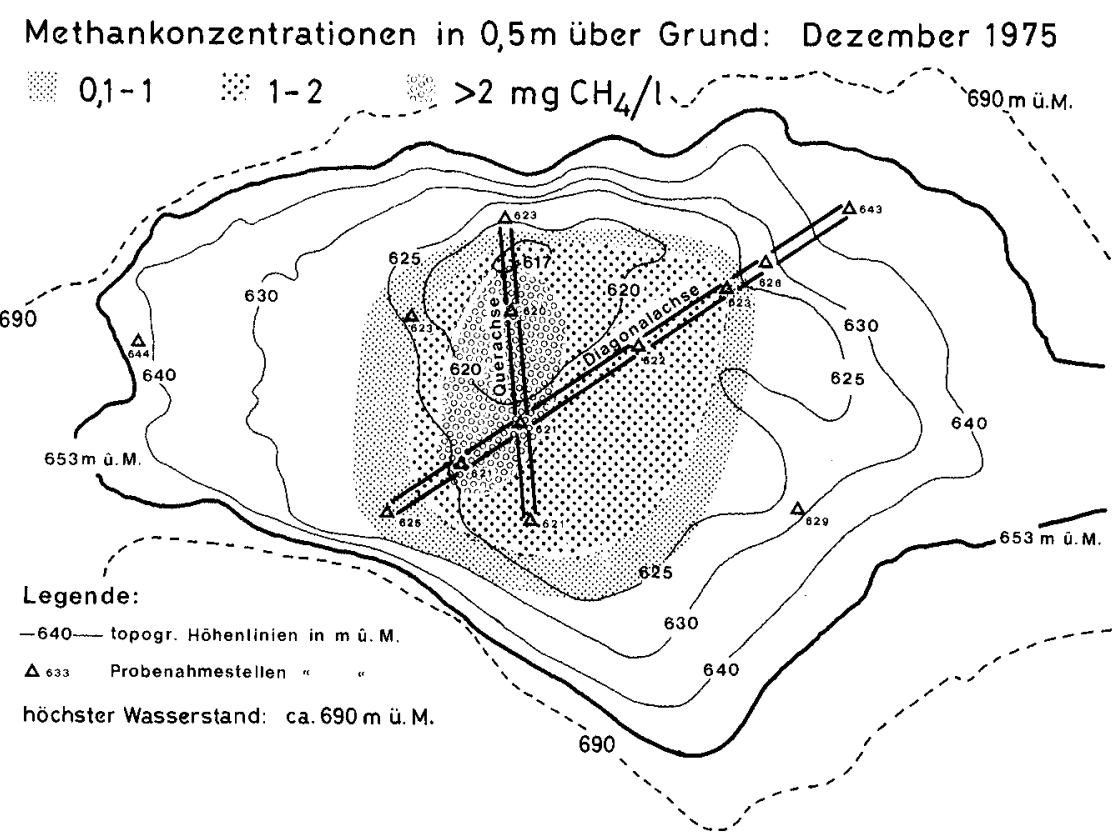

Abb. 14. Horizontale Verteilung der Methankonzentrationen über dem Grund des mittleren Lungernseebeckens, Ende Stagnation 1975.

Figure 14. Horizontal distribution of methane concentrations $0.5 \mathrm{~m}$ above the sediment of the central basin of Lake Lungern at the end of the stagnation period 1975 (legend: see fig. 10). 


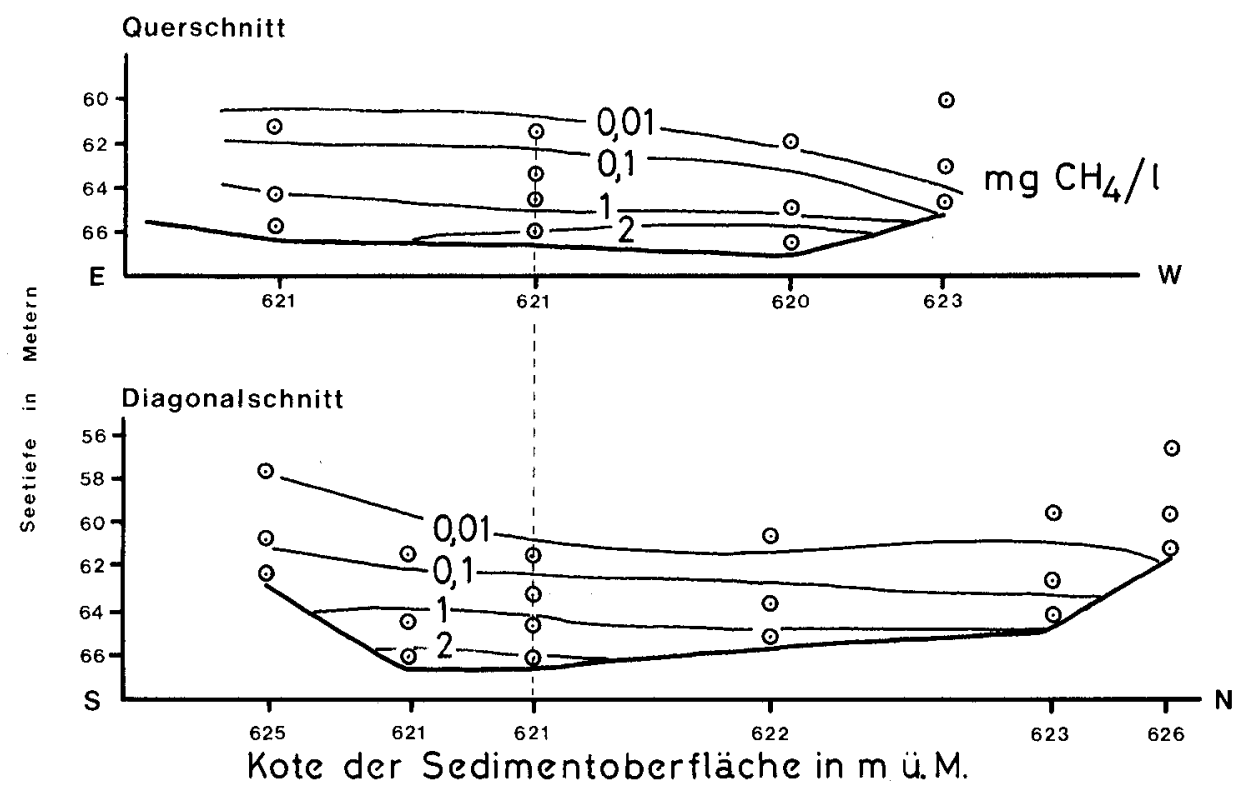

Abb. 15. Methankonzentrationen im Quer- und Diagonalschnitt über dem Grund des mittleren Lungernseebeckens im Dezember 1975. Die Schnittachsen sind in Abb. 14 eingezeichnet. Figure 15. Methane concentrations in the central basin of Lake Lungern in December 1975. Upper part: cross-section (Querschnitt), lower part: diagonal section of the basin (the axes are marked in fig. 14).

Left-hand scale: altitude above sealevel.

Die während der Stagnation im Hypolimnion des mittleren Beckens akkumulierten Methanmengen sind in Tabelle 4 zusammengestellt. Aus dieser Tabelle sind gleichzeitig die Isobathenflächen $\mathrm{F}_{0}$ ersichtlich, unterhalb welchen die Methankonzentration Werte von $10 \mu \mathrm{g} / 1$ übertraf.

Während der Seeabsenkung 1973/74 wurde an aufstossenden Methanblasen eine Altersbestimmung (siehe Kap.2.1) durchgeführt. Die $\mathrm{C}_{14}$-Aktivität der gemessenen Probe betrug $47 \%$ der in einer rezenten Methanprobe zu erwartenden Aktivität. Daraus folgt, dass das aufgefangene Methan, welches in Form von Gasblasen an die Seeoberfläche stieg, aus organischem Kohlenstoff mit einem Alter von $6270 \pm 90$ Jahren besteht.

\subsection{Methanflux an der Sedimentoberfläche}

Der Methanflux an der Sedimentoberfläche wurde einerseits aufgrund des Konzentrationsgradienten in Sedimentkernen, andererseits durch direkte Messungen mit Diffusionsglocken bestimmt. Das Tiefenprofil (Abb. 16) zeigt in den obersten $60 \mathrm{~cm}$ des Sedimentes mit zunehmender Sedimenttiefe eine lineare Zunahme der Methankonzentration.

Unter der Annahme, dass es sich beim beobachteten Gradienten um eine Steadystate-Situation handle, kann daraus geschlossen werden, dass ein Teil der Methan- 
quellen tiefer als $60 \mathrm{~cm}$ unter der Sedimentoberfläche liegt und entsprechend dem Konzentrationsgradienten von $1,4 \times 10^{-3} \mathrm{mg} / \mathrm{cm}^{4}$ ein vertikaler Methanflux von rund $1 \mathrm{mMol}$ an die Sedimentoberfläche stattfindet.

Tabelle 4. Methanakkumulation im Hypolimnionkompartiment von 620 bis $645 \mathrm{~m}$ ü. M. im mittleren Becken.

Table 4. Methane accumulation in the hypolimnion compartment of the central basin (620-645 m above sealevel).

\begin{tabular}{|c|c|c|c|}
\hline $\begin{array}{l}\text { Datum } \\
\text { der } \\
\text { Probenahme } \\
\text { Date of } \\
\text { sampling }\end{array}$ & $\begin{array}{l}\text { Akkumulierte Methe } \\
\text { Probenahmestelle } \\
\text { in } \mathrm{mMol} \mathrm{CH}_{4} / \mathrm{m}^{2} \\
\text { At the sampling site } \\
\text { in mmole } \mathrm{CH}_{4} / \mathrm{m}^{2} \\
\text { Accumulated amoun }\end{array}$ & $\begin{array}{l}\text { Unter der Fläche } F_{0} \\
\text { Fläche } \times 10^{3} \mathrm{~m}^{2} \\
\text { Below the area } F_{0} \\
\text { Area } \times 10^{3} \mathrm{~m}^{2}\end{array}$ & $\begin{array}{r}\mathrm{Mol} \mathrm{CH} 4 \\
\text { Mole } \mathrm{CH}_{4}\end{array}$ \\
\hline 26.8 . & 6,51 & 60 & 33 \\
\hline 10.9 & 8,34 & 120 & 493 \\
\hline 2.10 & 22,3 & 130 & 1486 \\
\hline 5.11 & 195,5 & 150 & 12425 \\
\hline 26.11. & 226,9 & 190 & 17960 \\
\hline 19.12 . & 352,5 & 200 & 32182 \\
\hline
\end{tabular}

Unterhalb der Fläche $F_{0}$ wurden $99 \%$ der gesamten Methanakkumulation akkumuliert.

Below the area $F_{0} 99 \%$ of the total methane accumulation have been accumulated.

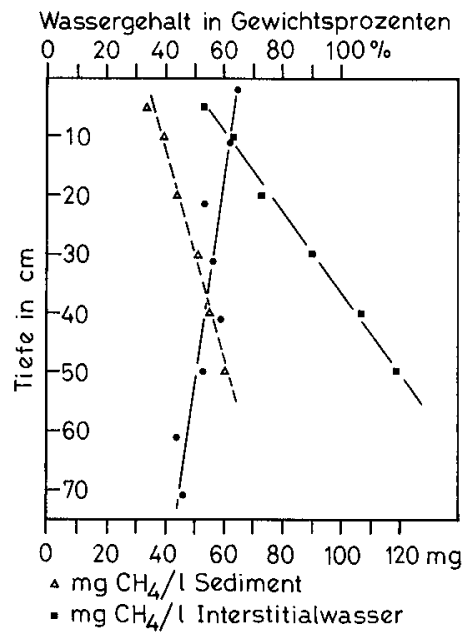

Abb. 16. Methankonzentrationen und Wassergehalte im Tiefenprofil des Seesedimentes im mittleren

Lungernseebecken. Wassergehalte berechnet aus einem Sedimentkern, in Gewichtsprozenten des Sedimentes. Methankonzentrationen: Mittelwerte aus vier Sedimentkernen in unmittelbarer Umgebung (tiefste Stelle). Konzentrationsangaben pro Liter Sediment und pro Liter Interstitialwasser.

Figure 16. Methane concentrations and water content in sediment cores from the central basin of Lake Lungern. Left-hand scale: depth in $\mathrm{cm}$ below sediment surface. Upper scale: water content in \% weight of the sediment sample (full circles). Lower scale: methane concentrations (mean values of four sediment cores) in $\mathrm{mg} / \mathrm{l}$ sediment (triangles) and in $\mathrm{mg} / \mathrm{l}$ interstitial water (squares). There is a linear relationship between depth, water content and methane concentrations. 
Im Mai 1976 wurde der Methanflux durch die Sedimentoberfläche mit drei Diffusionsglocken direkt gemessen. Zwei Glocken wurden mit $\mathrm{NaOH}$ versetzt, in einer dritten Glocke blieb das Wasser unverändert. Nach einer Expositionsdauer von 28 Tagen hatten sich in den beiden mit $\mathrm{NaOH}$ vergifteten Glocken 1035 bzw. $895 \mathrm{mg}$ $\mathrm{CH}_{4} / \mathrm{m}^{2}$ akkumuliert. Dies entspricht Methanfluxwerten von 2,0 bis $2,3 \mathrm{mMol} \mathrm{CH}_{4} /$ $\mathrm{m}^{2}$. Tag. In der dritten unvergifteten Glocke wurden nur $325 \mathrm{mg} \mathrm{CH} / \mathrm{m}^{2}$ akkumuliert. Daraus wird gefolgert, dass im unvergifteten System der Austritt von sedimentbürtigem Methan ins freie Wasser vermindert oder im freien Wasser Methan mikrobiell metabolisiert wird.

\subsection{Mikrobielle Methanoxidation im Wasser}

Die an der tiefsten Stelle des mittleren Beckens im sedimentnahen Wasser gemessenen Methanoxidationsraten sind in Abb. 19 dargestellt. Bis zum Juli beträgt die Methanoxidationsrate in allen Tiefen weniger als $1 \mu \mathrm{g} \mathrm{CH}_{4} / 1$. Tag. Im Zeitabschnitt Juli 1975 bis Februar 1976 entwickelt sich über dem Seegrund eine Zone, in der erhöhte Methanzehrungsraten gemessen wurden, wobei sowohl die Mächtigkeit der Zone als auch die absoluten Beträge der umgesetzten Methanmengen mit fortschreitender Stagnationsdauer zunehmen. Bemerkenswert ist die Tatsache, dass der Bereich maximaler Zehrungsraten (schraffierte Fläche in Abb.17) sich im Verlaufe der Stagnationsperiode vom Grund abhebt und damit nicht identisch ist mit dem Bereich maximaler Methankonzentrationen (Abb.13). Die Ursachen für dieses Verhalten sind vermutlich darin zu suchen, dass im Zeitabschnitt September bis Dezember die Sauerstoffkonzentrationen über dem Grund $\mathrm{zu}$ niedrig waren $\left(<0,1 \mathrm{mg} \mathrm{O}_{2} / 1\right.$, siehe Abb. 8), um maximale Methanzehrungsraten zu ermöglichen. Der massive Anstieg der Methanzehrung im Januar ist auf den zirkulationsbedingten Sauerstoffeintrag zurückzuführen.

Basierend auf den in monatlichen Abständen durchgeführten Messungen der Methanoxidationsraten wurden unter Berücksichtigung der Seemorphometrie die Methanoxidationsraten im gesamten Hypolimnion des mittleren Seebeckens abgeschätzt (Tab.5).

\subsection{Mikrobielle Methanoxidation an der Sediment-Wasser-Kontaktzone}

Im April 1976 wurden in den obersten $7 \mathrm{~mm}$ von zwei Sedimentkernen Umsatzraten von 153 bzw. $107 \mathrm{mMol} \mathrm{CH}_{4} / \mathrm{m}^{2}$. Tag gemessen. Entsprechende Kontrollmessungen in mit $\mathrm{NaOH}$ vergifteten Sedimentproben ergaben Umsatzraten von nur 1,5 bzw. $1,3 \mathrm{mMol} \mathrm{CH}_{4} / \mathrm{m}^{2}$. Tag. $\mathrm{Zu}$ dieser Zeit betrug die Methanumsatzrate im unmittelbar darüberstehenden Tiefenwasser $0,06 \mu \mathrm{Mol} \mathrm{CH}_{4} / 1$. Tag.

Diese Resultate zeigen übereinstimmend, dass

- die Kapazität zur mikrobiellen Methanoxidation im Sediment wesentlich grösser ist als im freien Wasser und

- dass unter günstigen Sauerstoffbedingungen das an die Sedimentoberfläche diffundierende Methan (1-2 $\mathrm{mMol} / \mathrm{m}^{2}$. Tag) bereits vor dem Übertritt ins Wasser oxidiert werden kann. 
Ein zentrales Problem dieser Arbeit besteht darin, abzuklären, welchen Einfluss die bakterielle Verwertung von Methan auf den Sauerstoffhaushalt des Lungernsees ausübt. Dafür ist es nötig, die quantitative Beziehung zwischen Methan- und

Kote in $m$ ü.M.

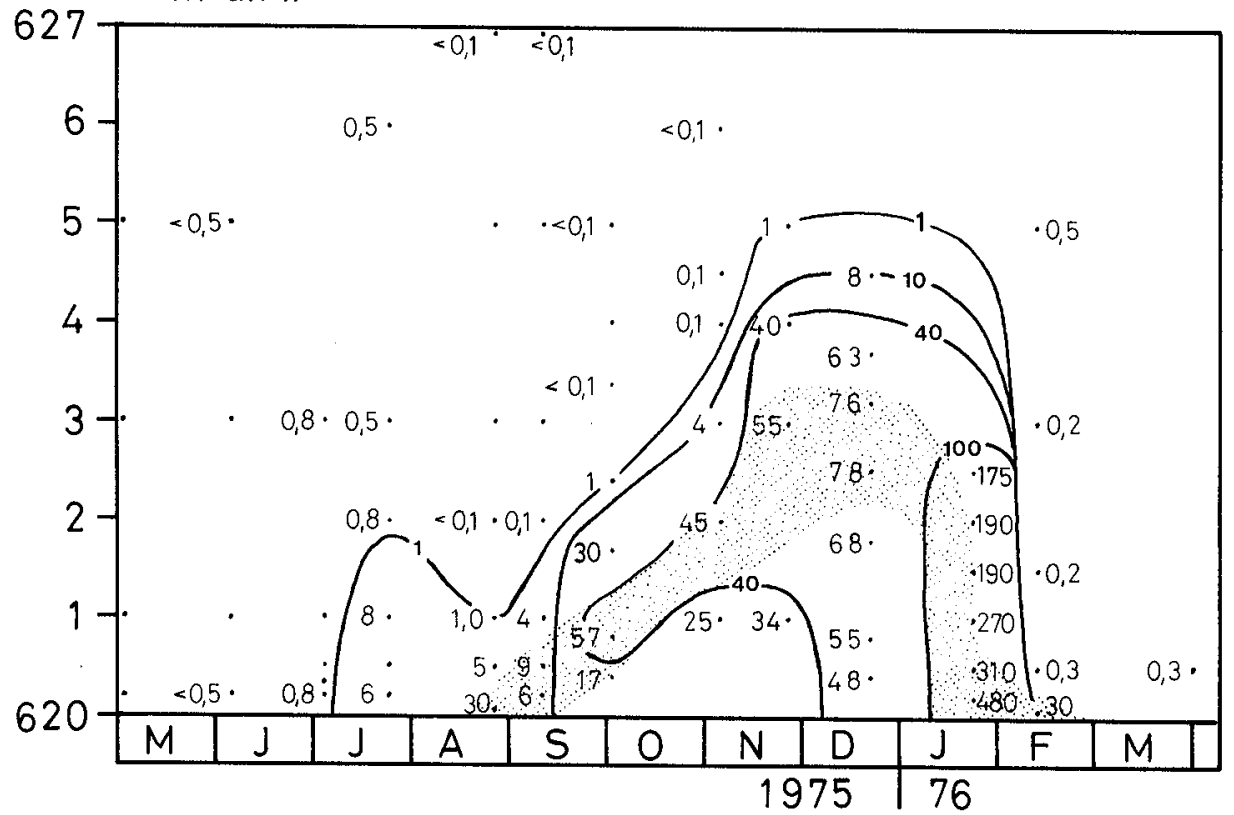

Abb. 17. Mikrobielle Methanzehrungsraten im mittleren Becken des Lungernsees 1975/76. Werte in $\mu \mathrm{g}$ $\mathrm{CH}_{4} / 1 \cdot \mathrm{Tag}$, dargestellt als Isopleten.

Figure 17. Microbial methane consumption in the central basin of Lake Lungern 1975/76. Values presented as isopleths in $\mu \mathrm{g} \mathrm{CH}_{4} / 1$. day. Left-hand scale: altitude above sealevel. The zone of maximum consumption in the free water is rising from the ground with progressing stagnation. The extremely high values in February are due to improved oxygen supply (see fig. 8).

Tabelle 5. Methanzehrung im Hypolimnion des mittleren Beckens, 1975.

Table 5. Methane consumption in the hypolimnion of the central basin, 1975.

\begin{tabular}{|c|c|c|c|}
\hline $\begin{array}{l}\text { Datum } \\
\text { der } \\
\text { Messung } \\
\text { Date of } \\
\text { sampling }\end{array}$ & $\begin{array}{l}\text { Methanoxidationsraten } \\
\text { Probenahmestelle } \\
\text { in } \mathrm{mMol} \mathrm{CH}_{4} / \mathrm{m}^{2} \cdot \mathrm{Tag} \\
\text { At the sampling site } \\
\text { in mmole } \mathrm{CH}_{4} / \mathrm{m}^{2} \cdot \mathrm{d}\end{array}$ & $\begin{array}{l}\text { Im mittleren Becken } \\
\text { in Mol } \mathrm{CH}_{4} / \mathrm{Tag} \\
\text { In the central basin } \\
\text { in mole } \mathrm{CH}_{4} / \mathrm{d}\end{array}$ & $\begin{array}{l}\mathrm{F}_{0} \text { in } \mathrm{m}^{2} \times 10^{3} \\
\mathrm{~F}_{0} \text { in } \mathrm{m}^{2} \times 10^{3}\end{array}$ \\
\hline 26.8. & 0,3 & ca. & 60 \\
\hline 10.9 & 0,52 & 32 & 120 \\
\hline 2.10 & 4,41 & 337 & 130 \\
\hline 5.11. & 5,40 & 450 & 150 \\
\hline 26.11 & 11,5 & 1450 & 190 \\
\hline 19.12 . & 16,8 & 1880 & 200 \\
\hline
\end{tabular}

Unter der Fläche $F_{0}$ wurden $99 \%$ der gesamten Methanzehrung gezehrt.

Below the area $F_{0} 99 \%$ of the total methane consumption have been consumed. 
Sauerstoffzehrung sowie der $\mathrm{CO}_{2}$-Produktion zu kennen. Da eine direkte Messung der aktuellen Sauerstoffzehrung in situ nicht möglich ist, wurde versucht, diese mit Hilfe der gemessenen $\mathrm{CH}_{4}$-Aufnahme und der $\mathrm{CO}_{2}$-Produktion über die stöchiometrischen Reaktionsformeln abzuschätzen:

Die Methanoxidation läuft formell in zwei Reaktionsschritten ab. Reaktion I dient zur Energiegewinnung der Bakterien durch vollständige Oxidation von $\mathrm{CH}_{4} \mathrm{zu} \mathrm{CO}_{2}$ ohne Einbau von C-Atomen in die Zelle:

$$
\mathrm{CH}_{4}+2 \mathrm{O}_{2}=\mathrm{CO}_{2}+2 \mathrm{H}_{2} \mathrm{O} \text {. }
$$

Reaktion II dient zur Biomassesynthese. Nach Redfield [39] nehmen wir dabei an, dass die wichtigsten chemischen Elemente im Verhältnis $1 \mathrm{C}: 2,5 \mathrm{H}: 1 \mathrm{O}$ inkorporiert werden. Somit kann eine «Biomasse-Einheit» als « $\mathrm{C} \mathrm{H}_{2,5} \mathrm{O}$ » bezeichnet werden.

$$
\begin{aligned}
\mathrm{CH}_{4}+0,875 \mathrm{O}_{2}=\left\langle\mathrm{CH}_{2,5} \mathrm{O} »\right. & +0,75 \mathrm{H}_{2} \mathrm{O} \\
x_{C_{4}}+2 \times \mathrm{O}_{2}= & x \mathrm{CO}_{2}+2 \mathrm{x} \mathrm{H}_{2} \mathrm{O} \\
(\mathrm{z}-\mathrm{x}) \mathrm{CH}_{4}+0,875(\mathrm{z}-\mathrm{x}) \mathrm{O}_{2}= & (\mathrm{z}-\mathrm{x}) \mathrm{CH}_{2,5} \mathrm{O}+0,75(\mathrm{z}-\mathrm{x}) \mathrm{H}_{2} \mathrm{O} \\
\mathrm{z} \mathrm{CH}_{4}+(0,875 \mathrm{z}+1,125 \mathrm{x}) \mathrm{O}_{2}= & x \mathrm{CO}_{2}+(\mathrm{z}-\mathrm{x}) \mathrm{CH}_{2,5} \mathrm{O} \\
& +(0,75 \mathrm{z}+1,25 \mathrm{x}) \mathrm{H}_{2} \mathrm{O} .
\end{aligned}
$$

Von einer $\mathrm{CH}_{4}$-Menge von $\mathrm{z}$ Mol können demnach $\mathrm{x}$ Mol nach Reaktion I und $(\mathrm{z}-\mathrm{x}) \mathrm{Mol}$ nach Reaktion II umgesetzt werden. Aus Abb. 18 ist ersichtlich, dass der

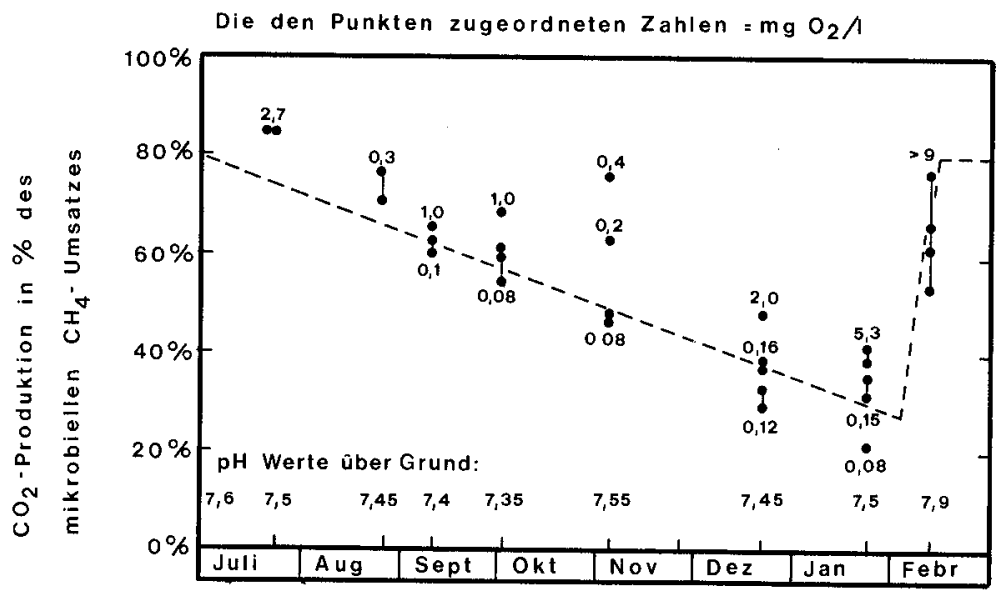

Abb. 18. Die durch Methanzehrung bedingte $\mathrm{CO}_{2}$-Produktion im mittleren Becken des Lungernsees 1975/76. $\mathrm{CO}_{2}$-Produktion in Mol-Prozenten des umgesetzten Methans. Die den Punkten zugeordneten Zahlen stellen die Sauerstoffkonzentrationen der gemessenen Wasserproben dar. Stöchiometrische Interpretation: siehe Kapitel 3.7.

Figure 18. $\mathrm{CO}_{2}$-production caused by methane consumption in the central basin of Lake Lungern 1975/ 76. $\mathrm{CO}_{2}$-production in mole fractions of the consumed methane (left-hand scale). The digits attributed to the points in the figure represent the $\mathrm{O}_{2}$-concentrations of the samples. $\mathrm{pH}$-values $0.5 \mathrm{~m}$ above the sediment are listed at the bottom of the figure. The relationship between $\mathrm{CO}_{2}$-production, $\mathrm{O}_{2}-$ concentration, and $\mathrm{pH}$, respectively, is not obvious, except for the begin of full overturn in February.

General trend: the mole fraction of $\mathrm{CO}_{2}$-production is sinking with progressive stagnation. 
Tabelle 6. Wăhrend der Stagnation umgesetzte Methanmengen im freien Wasser des tiefen Hypolimnions im mittleren Becken des Lungernsees.

Table 6. Amounts of methane transformed during the stagnation period in the free water of the deep hypolimnion in the central basin of Lake Lungern.

\begin{tabular}{lccr}
\hline $\begin{array}{l}\text { Periode } \\
\text { Period }\end{array}$ & $\begin{array}{l}\text { Intervall } \\
\text { in Tagen } \\
\text { Interval } \\
\text { in days }\end{array}$ & $\begin{array}{l}\text { Umgesetztes Methan in } \\
\mathrm{Mol} \mathrm{CH}_{4} \\
\text { Transformed methane in } \\
\text { mole } \mathrm{CH}_{4}\end{array}$ & $\begin{array}{r}\text { Dabei produziertes } \mathrm{CO}_{2} \\
\text { in } \mathrm{Mol}^{2}\end{array}$ \\
\hline $26.8 .-10.9$. & 15 & 380 & $\begin{array}{r}\text { Hereby produced } \mathrm{CO}_{2} \\
\text { in mole }\end{array}$ \\
$10.9 .-2.10$. & 22 & 5700 & 2460 \\
$2.10 .-5.11$. & 34 & 17000 & 6900 \\
$5.11 .-26.11$. & 21 \\
$26.11-19.12$. & 23 & 21000 & 17300 \\
$10.9 .-19.12$. & 100 & 41000 & 26700 \\
\hline
\end{tabular}

Tabelle 7. Sauerstoffverbrauch durch Methanzehrung im freien Wasser des mittleren Beckens, 1975.

Table 7. $\mathrm{O}_{2}$-consumption caused by the oxidation of methane in the central basin, 1975.

\begin{tabular}{|c|c|c|c|c|c|}
\hline \multirow{3}{*}{$\begin{array}{l}\text { Datum } \\
\text { Date }\end{array}$} & \multicolumn{2}{|c|}{ Probenahmestelle } & \multicolumn{3}{|c|}{ Mittleres Becken } \\
\hline & $\begin{array}{l}\mathrm{CH}_{4}-\mathrm{Zehrung} \\
\mathrm{CH}_{4} \text { consumed } \\
\text { At the sampling }\end{array}$ & $\begin{array}{l}\mathrm{O}_{2} \text { - Bedarf } \\
\mathrm{O}_{2} \text { consumed } \\
\text { site }\end{array}$ & $\begin{array}{l}\text { Fläche } \\
\text { Area } F_{0} \\
\text { In the centra }\end{array}$ & $\begin{array}{l}\mathrm{CH}_{4} \text {-Zehrung } \\
\mathrm{CH}_{4} \text { consumed } \\
\text { isin }\end{array}$ & $\begin{array}{r}\mathrm{O}_{2} \text {-Bedarf } \\
\mathrm{O}_{2} \text { consumed }\end{array}$ \\
\hline & $\begin{array}{l}\mathrm{mMol} \mathrm{CH}_{4} / \\
\mathrm{m}^{2} \cdot \mathrm{Tag}\end{array}$ & $\begin{array}{l}\mathrm{mMol} \mathrm{O}_{2} \prime \\
\mathrm{m}^{2} \cdot \mathrm{Tag}\end{array}$ & in $\mathrm{m}^{2} \times 10^{3}$ & $\begin{array}{l}\mathrm{Mol} \mathrm{CH}_{4} / \\
\mathrm{Tag}\end{array}$ & $\begin{array}{r}\mathrm{Mol} \mathrm{O}_{2} / \\
\mathrm{Tag}\end{array}$ \\
\hline 26.8. & 0,3 & 0,5 & 60 & 10 & 17 \\
\hline 10.9 & 0,52 & 0,82 & 120 & 32 & 49 \\
\hline 2.10 & 4,41 & 6,50 & 130 & 337 & 493 \\
\hline 5.11. & 5,40 & 7,36 & 150 & 450 & 621 \\
\hline 26.11. & 11,5 & 14,6 & 190 & 1450 & 1850 \\
\hline 19.12. & 16,8 & 20,5 & 200 & 1880 & 2290 \\
\hline
\end{tabular}

relative Anteil der methanbürtigen $\mathrm{CO}_{2}$-Produktion am Methanumsatz $\mathrm{x} / \mathrm{z}$ mit fortschreitender Stagnation abnimmt.

Aus Tabelle 5 und Abb. 18 lässt sich für einzelne Zeitabschnitte während der Stagnation abschätzen, welche Methanmenge im freien Wasser des tiefen Hypolimnions umgesetzt, wieviel $\mathrm{CO}_{2}$ dabei produziert und wieviel Sauerstoff konsumiert wurde. Tabelle 6 zeigt, dass im freien Wasser erst gegen Ende der Stagnationsperiode wesentliche Mengen an $\mathrm{CH}_{4}$ umgesetzt werden. Der durch die Methanzehrung bedingte Sauerstoffverbrauch ist in Tabelle 7 dargestellt. Daraus lässt sich ermitteln, dass im freien Wasser des mittleren Beckens im Zeitabschnitt Mai bis Dezember zur Methanoxidation rund $100000 \mathrm{Mol} \mathrm{O}_{2}$ verbraucht wurden.

\subsection{Mineralisation von organischem Kohlenstoff im Sediment}

Im Frühjahr 1976 wurde an der tiefsten Stelle des Sees in zwei Sedimentproben der Anteil des schwerflüchtigen organischen Kohlenstoffes (TOC) am Trockengewicht des Sedimentes bestimmt (Abb. 19) sowie vom 6. bis 27. April 1976 eine Sedimentfalle über dem Seegrund exponiert. Im aufgefangenen Material wurde ebenfalls der 


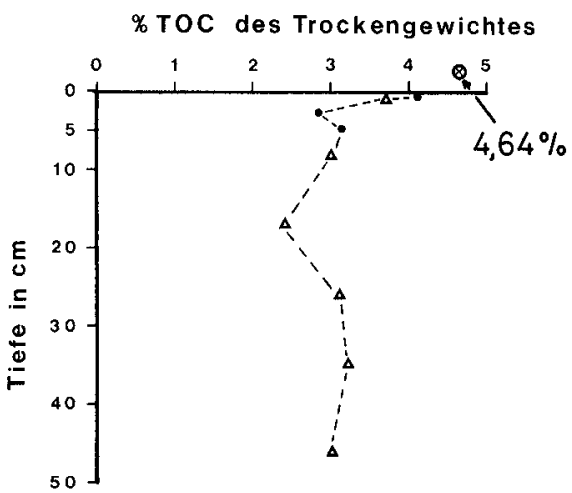

Abb. 19. Anteil des schwerflüchtigen organischen Kohlenstoffes (TOC) am Trockengewicht des Sedimentes im mittleren Lungernseebecken. Profil kombiniert aus zwei Kernen. Der Kreis oberhalb der $\mathrm{x}$-Achse steht für das Sedimentfallen-Material (exponiert vom 6. bis 27.4.76).

Figure 19. TOC-fraction (non volatile org. C) in the sediment (dry weight) of the middle basin of Lake Lungern. Profile combined from two cores. The circle above the $\mathrm{x}$-axis represents the TOC-fraction obtained in sediment traps $2 \mathrm{~m}$ above ground.

TOC-Anteil am Trockengewicht bestimmt. Dieser Anteil betrug 4,64\%. Im Sedimentkern pendelt sich der TOC-Anteil unterhalb $2,5 \mathrm{~cm}$ Tiefe bei etwa $3 \%$ ein. Daraus wurde abgeleitet, dass etwa ein Drittel des sedimentierten organischen Materials durch Abbauprozess in flüchtige Substanzen, wie $\mathrm{CO}_{2}$ oder $\mathrm{CH}_{4}$, umgewandelt worden ist und dass sich die restlichen zwei Drittel refraktär verhalten.

\section{Diskussion des Sauerstofthaushaltes im Hypolimnion des mittleren Lungernseebeckens}

In der zweiten Hälfte der Stagnation vom 24. Juli bis 19. Dezember 1975 wiesen, mit Ausnahme des Profils vom 2.Oktober 1975, sämtliche Sauerstoffprofile ein ähnliches Aussehen auf (Abb. 20).

Folgende Charakteristika sind festzustellen:

- Nahezu homogene vertikale Verteilung des Sauerstoffes zwischen den Koten 630 und $645 \mathrm{~m}$ ü. M., kleine Sauerstoffgradienten oberhalb von $630 \mathrm{~m}$ ü. M.,

- abrupte Änderung des Konzentrationsgradienten unterhalb der Kote $630 \mathrm{~m}$ ü. M.,

- mit fortschreitender Stagnationsdauer zunehmende Konzentrationsgradienten unterhalb von $630 \mathrm{~m}$ ü. M.

In Abb. 21 sind die Sauerstoffsenken dargestellt, welche im Hypolimnion wirksam sind. Sie werden folgendermassen definiert:

$\mathbf{J}=$ Direkte Oxidation von organischen sedimentierenden Partikeln während des freien Falls durch das Hypolimnion, ausgedrückt in Sauerstoffäquivalenten pro (Zeit $\times$ Volumen).

$\mathrm{J}_{\mathrm{z}}=$ Oxidation von organischen Partikeln, welche in der Tiefe $\mathrm{z}$ auf die Sedimentoberfläche gefallen sind, ausgedrückt in Sauerstoffäquivalenten pro (Zeit $\times$ Fläche). $\mathrm{M}_{\mathrm{s}}, \mathrm{M}_{\mathrm{m}}=$ Oxidation von Methan, welches aus dem Sedimentinnern in die Sedi- 


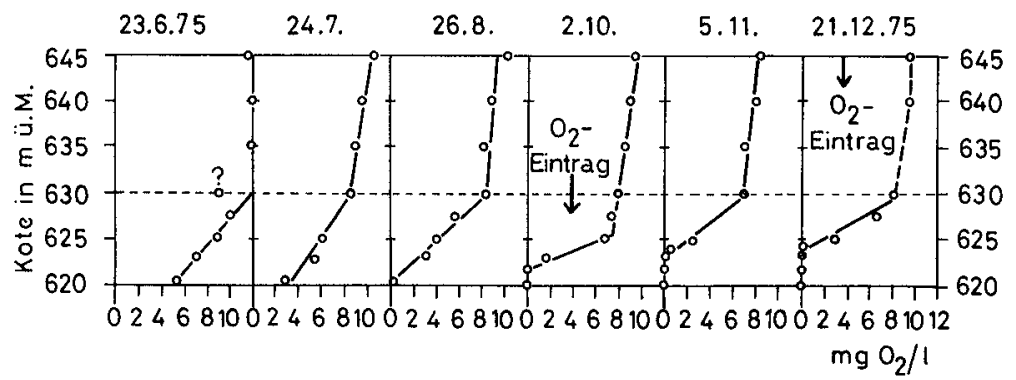

Abb. 20. Entwicklung der Sauerstoffprofile im mittleren Becken des Lungernsees vom 24. Juli bis 21. Dezember 1975.

Figure 20. Seasonal development of the hypolimnic $\mathrm{O}_{2}$-profiles in the central basin of Lake Lungern from 24 July until 21 December 1975 shows the formation of the following typical characteristics: 1. homogeneous $\mathrm{O}_{2}$-concentrations above $630 \mathrm{~m}$ above sealevel, 2. abrupt change in concentration gradients below $630 \mathrm{~m}, 3$. the gradients below $630 \mathrm{~m}$ increase with progressing stagnation.

ment-Wasser-Kontaktschicht diffundiert und dort in Gegenwart von Sauerstoff oxidiert wird, ausgedrückt in Sauerstoffäquivalenten pro (Zeit $\times$ Fläche).

In Abwesenheit von Sauerstoff kann es im überstehenden Wasser akkumuliert und dort teilweise oxidiert werden. Das Methan kann aus rezentem sedimentiertem Material entstanden sein $\left(\mathrm{O}_{2}\right.$-Senke $\left.\mathbf{M}_{\mathrm{s}}\right)$, oder es kann aus tieferen Sedimentschichten in Form von Erd- oder Sumpfgas an die Oberfläche gelangt sein $\left(\mathrm{O}_{2}\right.$-Senke $\left.\mathrm{M}_{\mathrm{m}}\right)$. $\mathrm{S}=$ Oxidierbare Partikel, welche aus dem Epilimnion durch die Isobathenfläche in $645 \mathrm{~m}$ ü. M. in das Hypolimnion sedimentieren, ausgedrückt in Sauerstoffäquivalenten pro (Zeit $\times$ Fläche).

$S, J, J_{z}$ und $M_{s}$ sind dabei durch folgende Gleichung verknüpft: $S=J_{z}+J \cdot z+M_{s}$. Ferner gilt: $S_{t o t}=S+M_{m}$, wobei $S_{t o t}$ für die Summe aller Sauerstoffsenken steht.

Diese Sauerstoffsenken beeinflussen die vertikale Verteilung der Sauerstoffkonzentrationen im Hypolimnion eines Sees in unterschiedlicher Weise:

- Die Volumensenke J bewirkt mit fortschreitender Stagnationsdauer eine tiefenunabhängige, gleichmässige Abnahme der Sauerstoffkonzentration.

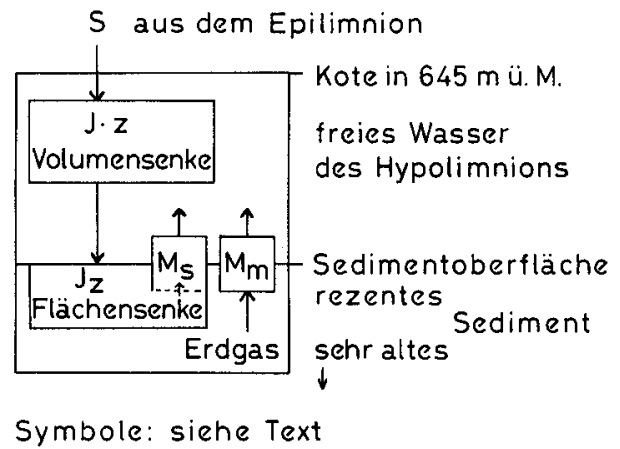

Abb. 21. Schematische Darstellung der Sauerstoffsenken im Hypolimnion.

Figure 21. Schematic presentation of the $\mathrm{O}_{2}$-sinks in the hypolimnion. 
_ Die Flächensenken $J_{z}$ und $M_{s}$ sind ursächlich mit den Senken $J$ und $S$ verknüpft $\left(S=J_{z}+J \cdot z+M_{s}\right)$ und vom Niveau des Sedimentbodens bzw. von der Sedimentationsstrecke $\mathrm{z}$ abhängig.

- Die Flächensenke $M_{m}$ wird als tiefenunabhängig angenommen.

Wenn der vertikale und der horizontale Transport des Sauerstoffes bekannt sind, kann bei bekannten $J, S$ und $M_{m}$ die zeitliche Veränderung der Sauerstoffkonzentration in jedem beliebigen Seekompartiment berechnet werden. Da es sich gezeigt hat, dass die Sauerstoffisopleten im wesentlichen horizontal verlaufen, wird davon ausgegangen, dass die horizontale Diffusion sehr, bzw. «unendlich», gross ist. Alle verwendeten Grössen sind daher nur noch von der Zeit ( $t$ ) und der Tiefe (z) abhängig, und der vertikale Sauerstofftransport kann mit Hilfe eines eindimensionalen Modelles beschrieben werden. Da das Modell (Dimension $=\mathrm{z}$-Achse) die Isobathenflächen (nicht aber ihre Form) in Abhängigkeit von der Seetiefe z berücksichtigt, hat es aber trotzdem einen pseudo-dreidimensionalen Charakter.

Das modellierte Seekompartiment wird oben durch die Isobathenfläche der Kote $645 \mathrm{~m}$ ü. M., seitlich und unten durch die Sedimentoberflächen begrenzt (Abb. 22). Die Kote in $645 \mathrm{~m}$ ü.M. ist die oberste Kote, welche das mittlere Becken von den beiden andern begrenzt.

Eine Sensitivitätsanalyse mit dem Rechenmodell ergab, dass die beobachteten charakteristischen Sauerstoffprofile (Abb.20) nur dann simuliert werden können, wenn der vertikale Diffusionskoeffizient $\mathrm{K}_{\mathrm{z}}$ im Kompartiment $620-630 \mathrm{~m}$ ü.M. viel kleiner als $0,1 \mathrm{~cm}^{2} / \mathrm{sec}$ ist [4]. Simulationen, welche den charakteristischen Knick des Sauerstoffprofils in $630 \mathrm{~m}$ ü. M. noch gut erkennen lassen, wurden $\mathrm{mit}_{\mathrm{z}} \leq 0,01$ $\mathrm{cm}^{2} / \mathrm{sec}$ erzielt.

Die Form der beobachteten $\mathrm{O}_{2}$-Profile (Abb. 20) lässt vermuten, dass im Lungernsee unterhalb der Kote $630 \mathrm{~m}$ ü. M. in erster Linie $\mathrm{O}_{2}$-Flächensenken für die beobachtete Sauerstoffzehrung verantwortlich sind. Um dies quantitativ zu überprüfen, wurde

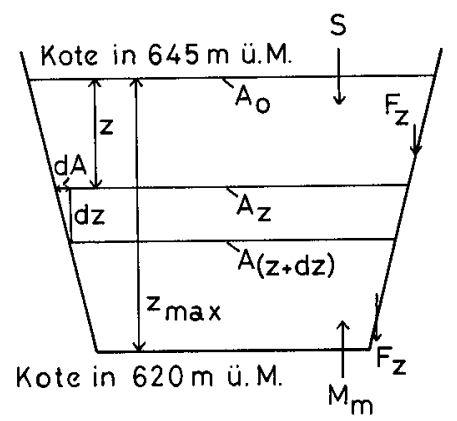

Abb.22. Dimensionen des Hypolimnionkompartimentes im eindimensionalen Diffusionsmodell. $\mathrm{A}=$ horizontale Querschnittfläche (=Isobathenfläche, Kote). $\mathrm{z}=$ vertikale Ausdehnung (Seetiefe,

$\mathrm{z}=0 \mathrm{~m}$ in $645 \mathrm{~m}$ ü. M.). $\mathrm{z}_{\max }=$ maximale Seetiefe des Hypolimnionkompartimentes $(25 \mathrm{~m})$.

$\mathrm{S}=$ oxidierbares organisches Material in $\mathrm{O}_{2}$-Äquivalenten. $\mathrm{F}_{2}=\mathrm{O}_{2}$-Flux an die Sedimentoberfläche in der Tiefe $\mathrm{z} . \mathrm{M}_{\mathrm{m}}=$ Erdgas-Flux an die Sedimentoberfläche in $\mathrm{O}_{2}$ - ̈̈quivalenten.

Figure 22. Dimensions of the hypolimnion compartment in the one dimensional diffusion model.

$\mathrm{A}=$ horizontal areas in the lake. $\mathrm{z}=$ vertical extension, depth $(\mathrm{z}=0 \mathrm{~m}$ in $645 \mathrm{~m}$ above sealevel).

$\mathrm{z}_{\max }=$ maximum depth of the hypolimnion compartment $(=25 \mathrm{~m}) . \mathrm{F}_{\mathrm{z}}=\mathrm{O}_{2}$-Flux to the sediment-water boundary in the depth $\mathrm{z} . \mathrm{S}, \mathrm{M}_{\mathrm{m}}$ : see text. 
in Abb.23 für zwei Zeitabschnitte die beobachtete Sauerstoffzehrung in den einzelnen Boxen dem jeweiligen Verhältnis zwischen Boxenvolumen und angrenzender Sedimentfläche $(\Delta \mathrm{A} / \mathrm{V})$ gegenübergestellt (die geometrische Definition der einzelnen Boxen kann aus Abb. 5 entnommen werden). Aus der linearen Beziehung zwischen den beiden Parametern ergibt sich eine in erster Näherung tiefenunabhängige Flächensenke $\left(J_{z}+M_{s}+M_{m}\right)$ von 150 bis $160 \mathrm{mg} \mathrm{O} / \mathrm{m}^{2}$. Tag.

Abb. 23 zeigt auch, dass bei linearer Extrapolation für $\Delta \mathrm{A} / \mathrm{V}=\mathrm{O}$ die Sauerstoffzehrung nicht Null wird. Daraus wird geschlossen, dass im Zeitabschnitt März bis November nicht nur an der Sedimentoberfläche, sondern auch im freien Wasser (Volumensenke J) täglich etwa 5 bis $10 \mathrm{mg} \mathrm{O} / \mathrm{m}^{3}$. Tag gezehrt werden. Bei diesen Angaben handelt es sich um Minimalwerte, weil sie als Netto-Messwerte die ständige Nachlieferung von Sauerstoff durch Eddydiffusionsprozesse nicht berücksichtigen.

Die Primärproduktion des Lungernsees beträgt nach Gächter und Bossard [18] im Zeitabschnitt 1. März bis 1 . November $96 \mathrm{~g} \mathrm{C} / \mathrm{m}^{2}$. Aufgrund der Untersuchungen

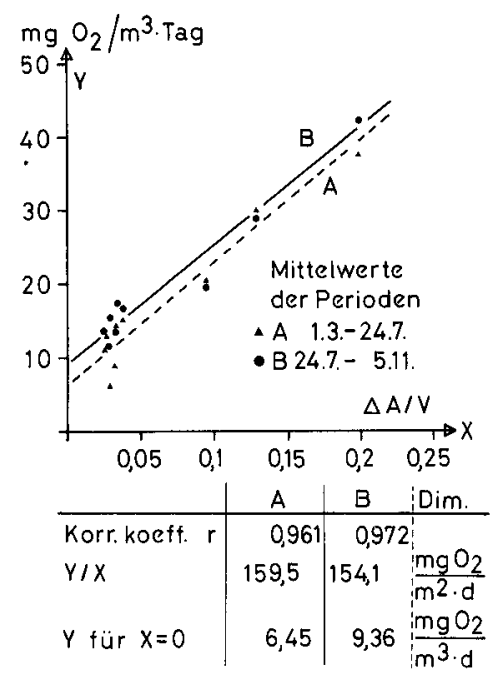

Abb.23. Vergleich der beobachteten $\mathrm{O}_{2}$-Nettozehrungsraten der einzelnen Kompartimente (Y) mit den dazugehörenden Verhältniszahlen $(\mathrm{X})$ zwischen angrenzender Sedimentfläche und Volumen $(\Delta \mathrm{A} / \mathrm{V})$, ausgehend von Abb.5.

Legende: Die Geraden A und B beschreiben eine lineare Beziehung zwischen X und Y für die Perioden vom 1. März bis 24. Juli 1975 (A) bzw. vom 24. Juli bis 5. November 1975 (B), wie sie von einer tiefenunabhängigen Flächensenke verursacht wird. Die Steigung Y/X repräsentiert die $\mathrm{O}_{2}-\mathrm{Zehrung}$ der Flächensenke des gesamten Kompartimentes (620-645 m ü. M.). Der Schnittpunkt der Geraden mit der $\mathrm{Y}$-Achse $\left(\mathrm{Y}_{0}\right)$ repräsentiert die $\mathrm{O}_{2}$-Zehrung der Volumensenke.

Figure 23. Comparison between the observed $\mathrm{O}_{2}$ net consumption and the area/volume ratio $(\Delta \mathrm{A} / \mathrm{V}$, for $\Delta \mathrm{A}=\mathrm{dA}=\mathrm{A}_{\mathrm{z}}-\mathrm{A}_{(\mathrm{z}+\mathrm{dz})}$, according to fig. 22) in the different boxes (defined in fig. 5) of the hypolimnion compartment.

Comment: The straight lines $\mathrm{A}$ and $\mathrm{B}$ represent a linear relationship between $\mathrm{X}$ and $\mathrm{Y}$ for the periods from 1 March until 24 July 1975 (A) and from 24 July until 5 November 1975 (B), respectively, caused by water-sediment boundary fluxes, which are independent of the depth $\mathrm{z}$. The slope $\mathrm{Y} / \mathrm{X}$ represents the $\mathrm{O}_{2}$ net consumption due to the boundary flux, the $\mathrm{Y}$-intercept represents the $\mathrm{O}_{2}$ net consumption in the free water (volume sink). 
von Bloesch [6] und Ohle [35] kann angenommen werden, dass höchstens $20 \%$ des autochthon produzierten organischen Kohlenstoffes bis ins Hypolimnion gelangen und davon an der tiefsten Stelle des Sees während des Absinkens durch das Hypolimnion höchstens $50 \%$ mineralisiert werden.

Aufgrund dieser Angaben kann davon ausgegangen werden, dass im Mittel täglich etwa $79 \mathrm{mg}$ org. $\mathrm{C} / \mathrm{m}^{2}$ ins Hypolimnion sedimentieren. Je nach Hypolimniontiefe wird davon bereits während des Absinkens ein grösserer oder kleinerer Anteil, höchstens aber $40 \mathrm{mg}$ org. $\mathrm{C} / \mathrm{m}^{2}$. Tag, mineralisiert. Daraus berechnet sich die Grösse der Sauerstoff-Volumensenke J auf

$$
\mathrm{J}=\frac{40 \mathrm{mg} \mathrm{C} / \mathrm{m}^{2} \cdot \mathrm{Tag}}{25 \mathrm{~m}} \cdot 3,47 \mathrm{mg} \mathrm{O}_{2} / \mathrm{mg} \mathrm{C}=5,5 \mathrm{mg} \mathrm{O}_{2} / \mathrm{m}^{3} \cdot \mathrm{Tag},
$$

was mit dem aus Abb. 23 abgeleiteten Wert von 5 bis $10 \mathrm{mg} \mathrm{O} / \mathrm{m}^{3} \cdot$ Tag gut übereinstimmt.

Aufgrund dieser Abschätzungen muss davon ausgegangen werden, dass an der tiefsten Stelle täglich etwa $39 \mathrm{mg}$ autochthon produziertes $\mathrm{C} / \mathrm{m}^{2}$ auf die Sedimentoberfläche auftreffen. Bei einer 33prozentigen Oxidation (vgl. Abschnitt 3.7) würden täglich nur $45 \mathrm{mg} \mathrm{O} / \mathrm{m}^{2}$ verbraucht, bei einer 100prozentigen Oxidation höchstens $135 \mathrm{mg} \mathrm{O} / \mathrm{m}_{2}^{2}$. Auf S. 243 wurde aber eine tiefenunabhängige Flächensenke von mindestens 150 bis $160 \mathrm{mg} \mathrm{O} / \mathrm{m}^{2}$. Tag postuliert. Daraus folgt, dass die autochthone Primärproduktion die beobachtete Sauerstoffzehrung im tiefen Hypolimnion des Sees nicht zu erklären vermag.

Bei guter Sauerstoffversorgung wird das in die Sedimentoberfläche diffundierende Methan von 2,0 bis 2,3 $\mathrm{mMol} \mathrm{CH}_{4} / \mathrm{m}^{2}$. Tag bereits vor dem Austreten ins Wasser quantitativ oxidiert (siehe S. 236).

Aufgrund der vorliegenden Untersuchungen muss dieses Methan aus zwei verschiedenen Quellen stammen:

- Der durchschnittliche Flux von fossilem Methan aus tieferen Sedimentschichten beträgt $1 \mathrm{mMol} \mathrm{CH}_{4} / \mathrm{m}^{2}$. Tag (Kap. 3.4).

- Die rezente Fermentation dürfte für eine durchschnittliche $\mathrm{CH}_{4}$-Produktion von $2,2-1=1,2 \mathrm{mMol} / \mathrm{m}^{2}$. Tag verantwortlich sein (Kap.3.4).

Dieses Verhältnis von rezentem zu fossilem Methan von etwa 1,2 wird auch durch die $\mathrm{C}_{14}$-Altersbestimmung gestützt. Wenn das gemessene Alter von $6270 \mathrm{Jahren}$ als «Mischalter» von rezentem Methan und fossilem Erdgas interpretiert wird, so müsste ein Verhältnis von fossilem zu rezentem Methan von 1,1 in Rechnung gestellt werden.

Zur vollständigen Oxidation des rezenten Methans werden $77 \mathrm{mg} \mathrm{O}_{2} / \mathrm{m}^{2}$. Tag benötigt, zur vollständigen Oxidation des fossilen Methans $64 \mathrm{mg} \mathrm{O} / \mathrm{m}^{2} \cdot$ Tag. Aufgrund dieser Abschätzung kommen wir zum Schluss, dass auch die $\mathrm{CH}_{4}$ Oxidation allein nicht ausreicht, um die beobachtete flächenspezifische Sauerstoffzehrung von mindestens 150 bis $160 \mathrm{mg} \mathrm{O} / \mathrm{m}^{2}$. Tag zu erklären.

Im folgenden wird versucht, die Belastung des Hypolimnions mit abbaubarer organischer Substanz durch Anpassung des beschriebenen Modells an die beobachteten Daten abzuschätzen. Dabei wurde die zeitliche Veränderung der $\mathrm{O}_{2}$-Konzentration am oberen Rand des simulierten Kompartimentes berücksichtigt und die 
Belastung des Hypolimnions mit partikulärer abbaubarer organischer Substanz so lange variiert, bis Modell und Wirklichkeit übereinstimmten.

Es wurden ferner folgende Randbedingungen berücksichtigt:

- Die $\mathrm{O}_{2}$-Anfangskonzentration betrug am 1.März in allen Schichten $11 \mathrm{mg} / 1$ (Sättigungskonzentration bei vollständiger Durchmischung).

- Zur Mineralisation von absinkendem organischem Material werden 5,5 $\mathrm{mg} \mathrm{O}_{2}$ ' $\mathrm{m}^{3}$. Tag benötigt (siehe S. 244).

- Zur Oxidation von fossilem Methan werden täglich $64 \mathrm{mg} \mathrm{O}_{2}$ pro $\mathrm{m}^{2}$ benötigt. Abb. 24 zeigt, dass Modell und Wirklichkeit sowohl im September als auch im November übereinstimmen, wenn der Sauerstoffbedarf des ins Hypolimnion sedimentierten Materials $210 \mathrm{mg} \mathrm{O} / \mathrm{m}^{2}$. Tag beträgt. Dieser Wert ist als Minimalwert zu betrachten, da er die Oxidation von organischer Substanz im Sediment durch $\mathrm{NO}_{3}$ und $\mathrm{SO}_{4}$ nicht berücksichtigt. Er übertrifft jedoch den Sauerstoffbedarf des autochthon produzierten organischen Materials, was damit zu erklären ist, dass der See auch mit allochthonem, abbaubarem Material belastet wird.

Um zu überprüfen, wie sich die Belastung des Lungernsees mit fossilem Methan auf seinen Sauerstoffhaushalt auswirkt, wurde in Abb.25 die Entwicklung der Sauerstoffkonzentration im untersten Kompartiment (620-622,5 m ü. M.) mit und ohne Oxidation von fossilem Methan simuliert.

Aus der Abbildung kann entnommen werden, dass das fossile Methan den Sauerstoflhaushalt des Lungernsees entscheidend beeinflusst. Da die Teilzirkulation aufgrund der Temperaturmessungen bereits im November und die Vollzirkulation im Dezember einsetzt, würde im Lungernsee ohne die Oxidation des fossilen Methans nie Anaerobie auftreten.

In der Periode vom 2. Oktober bis 5. November 1975 wurden $10900 \mathrm{Mol} \mathrm{CH}_{4}$ akkumuliert (siehe Tab.4) und $6900 \mathrm{Mol} \mathrm{CO}_{2}$ produziert (siehe Tab.6). Bei einer

1. März - 10. Sept.

Kote in $m$ ü.M.

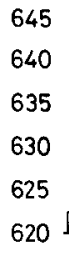

645
640
635
630
625
620

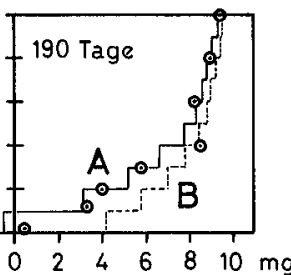

- gemessene $\left[\mathrm{O}_{2}\right]$ am 10. Sept. bzw. 5. Nov.

A mit, $B$ onne fossiles Methan
1. März - 5. Nov.

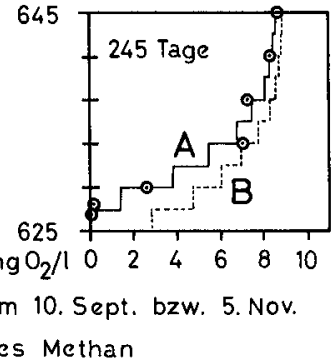

Abb.24. Simulation der Sauerstoffzehrung mit dem Rechenmodell zwischen dem 1. März und dem 1. November im mittleren Lungernseebecken $(A=$ mit, $B=$ ohne Oxidation von fossilem Methan). Figure 24. Simulation of the $\mathrm{O}_{2}$-consumption in the hypolimnion compartment of the central basin by aid of the mathematical model for the period between 1 March and 1 November $(A=$ with, $B=$ without oxidation of fossile methane). Duration: left figure 190, right figure 245 days.

Simulationsbedingungen/Conditions for the simulation: $K_{z}=0,01 \mathrm{~cm}^{2} / \mathrm{sec}$ in allen Tiefen (at all depths):

A: $\mathrm{S}=210 \mathrm{mg} \mathrm{O}_{2} / \mathrm{m}^{2} \cdot \mathrm{Tag}, \mathrm{J}=5,5 \mathrm{mg} \mathrm{O} / \mathrm{m}^{3} \cdot \mathrm{Tag}, \mathrm{M}_{\mathrm{m}}=64 \mathrm{mg} \mathrm{O}_{2} / \mathrm{m}^{2} \cdot \mathrm{Tag}$.

B: $\mathrm{S}=210 \mathrm{mg} \mathrm{O} / \mathrm{m}^{2} \cdot \mathrm{Tag}, \mathrm{J}=5,5 \mathrm{mg} \mathrm{O} / \mathrm{m}^{3} \cdot \mathrm{Tag}, \mathrm{M}_{\mathrm{m}}=0 \mathrm{mg} \mathrm{O} \mathrm{O}_{2} / \mathrm{m}^{2} \cdot \mathrm{Tag}$. 


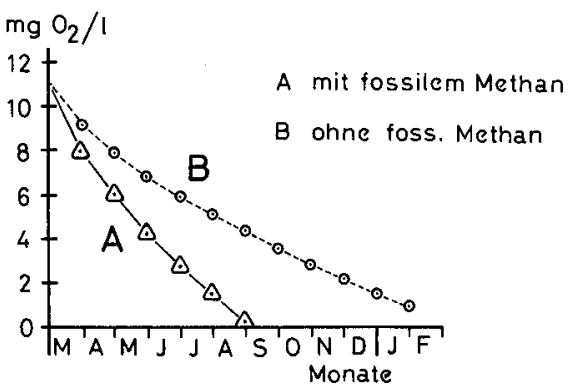

Abb.25. Simulation der Entwicklung der mittleren Sauerstoffkonzentration im Kompartiment 620 $622,5 \mathrm{~m}$ ü. M. Simulationsbedingungen: siehe Abb. 24 .

Figure 25. Simulation of the temporal development of the average oxygen concentration in box No. 10 (according to fig. 5 the lowest box of the hypolimnion compartment). Conditions for the simulation: see figure $24 . \mathrm{O}_{2}$-starting concentration on $1 \mathrm{March}: 11 \mathrm{mg} / 1$ in all depths.

methanproduzierenden Fläche $F_{0}$ von $140000 \mathrm{~m}^{2}$ errechnet sich daraus eine durchschnittliche Methanproduktion von $3,75 \mathrm{mMol} / \mathrm{m}^{2}$. Tag. Im Zeitraum vom 5. November bis 19. Dezember 1975 betrug die Methanakkumulation $14200 \mathrm{Mol}$, die $\mathrm{CO}_{2}$-Produktion $17300 \mathrm{Mol}$. Bei einem mittleren $\mathrm{F}_{0}$ von $195000 \mathrm{~m}^{2}$ betrug die durchschnittliche Methanproduktion somit 3,67 mMol/ $\mathrm{m}^{2} \cdot$ Tag. Diese Werte liegen wesentlich höher als die im Mai gemessene Methandiffusion von 2,0 bis 2,3 mMol/ $\mathrm{m}^{2}$. Tag.

Aufgrund der Untersuchung der Sedimente (siehe Abb.19) kann geschlossen werden, dass sich der Abbau von sedimentierter organischer Substanz über einige Jahre erstreckt. An der Oberfläche wird zur Mineralisation (sofern vorhanden) Sauerstoff, in tieferen Sedimentschichten Nitrat (Dentrifikation), Sulfat (Sulfatreduktion) und organische Substanz (Fermentation) benötigt. Das entstehende Methan diffundiert an die Sedimentoberfläche und wird dort oxidiert oder tritt ins freie Wasser über. Da bei fortschreitender Stagnationsdauer das Redoxpotential in den Sedimenten ständig abnimmt, muss die rezente Methanproduktion auf Kosten der aeroben Mineralisation ständig anwachsen.

\section{Zusammenfassung}

1975/76 wurden im Lungernsee regelmässig Felduntersuchungen über die Temperatur, die Sauerstoff- und Methankonzentration sowie über die mikrobielle Methanzehrung im freien Wasser durchgeführt. Daraus wurden in einem definierten Hypolimnionkompartiment für die Stagnation die Sauerstoffzehrung, die Methanoxidation und die Methanakkumulation im Wasser bilanziert.

Aufgrund eines stöchiometrischen Modells, welches die Methan- und Sauerstoffzehrung sowie die $\mathrm{CO}_{2}$-Produktion in direkte Beziehung zueinander setzt, wurde der durch Methanoxidation bedingte Sauerstoffverbrauch während der Stagnation im mittleren Becken berechnet. 
Die Methandiffusion durch die Sediment-Wasser-Kontaktzone wurde direkt gemessen. Der fossile Anteil des Methans wurde durch die Messung des Konzentrationsgradienten in Sedimentkernen und durch Altersbestimmung von aufstossendem Methan bestimmt.

Mit Hilfe eines pseudo-dreidimensionalen Diffusionsmodells wurden die Rollen verschiedener Sauerstoffsenken und des vertikalen Sauerstofftransportes im Sauerstoffhaushalt des Lungernsees untersucht. $\mathrm{Zu}$ diesem $\mathrm{Zweck}$ wurden die Sauerstoffsenken in Volumen- und Flächensenken unterteilt.

Diese Untersuchungen brachten folgende Erkenntnisse über den Sauerstoffhaushalt im Hypolimnion des mittleren Lungernseebeckens: Das Hypolimnionkompartiment unter der Isobathenfläche $645 \mathrm{~m}$ ü. M. zirkuliert von Januar bis März und stagniert von März bis Januar. Im oberen Teil des Hypolimnions dauert die Stagnationsphase nur von März bis November. Die horizontale Durchmischung ist in allen Schichten gut. Im oberen Teil wird der Sauerstoffhaushalt in erster Linie durch die Volumensenke (Oxidation von sedimentierenden Partikeln) geprägt. Im unteren Teil des Kompartimentes prägen in erster Linie die Flächensenken die Entwicklung des Sauerstoffprofils. Dies führt dazu, dass sich im Verlaufe der Stagnation ein charakteristisches $\mathrm{O}_{2}$-Profil ausbildet, welches im oberen Teil relativ hohe $\mathrm{O}_{2}$-Konzentrationen mit kleinem $\mathrm{O}_{2}$-Gradienten, im unteren Teil jedoch einen grossen $\mathrm{O}_{2}$-Gradienten aufweist. Der durch die Eddydiffusion bedingte Sauerstofftransport durch die Isobathenfläche $645 \mathrm{~m}$ ü. M. beträgt während der Aufwärmephase des Hypolimnionkompartimentes von Mai bis Oktober etwa 25\% der beobachteten Sauerstoffnettozehrung.

Trotz den niedrigen Primärproduktionsraten des Sees von nur $120 \mathrm{~g} \mathrm{C} / \mathrm{m}^{2} \cdot \mathrm{Jahr}$ sinkt die Sauerstoffkonzentration an der tiefsten Stelle des Sees bereits im Juli wesentlich unter $4 \mathrm{mg} \mathrm{O}_{2} / 1$.

Die Untersuchungen zeigen, dass der $\mathrm{O}_{2}$-Haushalt des Sees wesentlich durch die mikrobielle Oxidation von Methan beeinflusst wird. Das an die Sediment-WasserKontaktzone diffundierende Methan stammt zum Teil aus Erdgas $(1 \mathrm{mMol} /$ $\mathrm{m}^{2}$. Tag) und zum Teil aus der Reduktion von rezent sedimentiertem organischem Material (1,2 $\mathrm{mMol} / \mathrm{m}^{2}$. Tag) im Zeitraum von Februar bis November). Im Herbst bewirkt die sich ausbreitende Anaerobie an der Sedimentoberfläche ein Absinken des Redoxpotentials im Sediment und damit eine vorübergehend erhöhte Methanproduktion in rezenten Sedimenten (von November bis Januar beträgt sie im Schnitt etwa 3,7 $\mathrm{mMol} \mathrm{CH}_{4} / \mathrm{m}^{2}$. Tag). Das niedrige Redoxpotential an der Sediment-Wasser-Kontaktzone erlaubt keine Methanoxidation mehr und das Methan diffundiert in das freie Wasser. Die mikrobielle Oxidation dieses Methans im freien Wasser verzögert die zirkulationsbedingte Sauerstoffsättigung im untersten Teil des Kompartimentes bis Ende Januar.

Aufgrund der durchgeführten Simulationsrechnungen mit dem in Kapitel 4 beschriebenen Modell wurden die Folgerungen gezogen, dass der Lungernsee ohne die Oxidation von Erdgas auch an der tiefsten Stelle während des ganzen Jahres aerob bleiben würde. Die festgestellte Anaerobie im Zentrum des mittleren Beckens verursacht tiefgreifende qualitative Veränderungen (Nitratreduktion, Phosphorrücklösung, erhöhte Methanproduktion im Sediment bzw. -oxidation im freien Wasser gegen Ende der Stagnation). 


\section{SUMMARY}

\section{Introduction}

Lake Lungern is the uppermost link of a chain of lakes in the Swiss prealps. Today it is used for electricity production, it is however of preglacial origin. Only $20 \%$ of the inflowing water stems from the natural drainage area, which has been artificially enlarged by deviating water from neighbouring valleys. Inflow and outflow are situated closely together. The surface water level changes yearly by $15 \mathrm{~m}$. The maximum volume is 62 million $\mathrm{m}^{3}$, the maximum depth is $72 \mathrm{~m}$ in the central basin (see fig. 1: topography of the lake). The annual water charge amounts to $100-200$ million $\mathrm{m}^{3}$.

According to monthly investigations in 1971 [18] the general characteristics of the lake are described as following:

- According to the primary production, secchi-depth and nutrient concentrations the lake is oligo- to mesotrophic.

- The observed anaerobiosis in the deep hypolimnion at the end of the stagnation, linked with the reduction of nitrate and with the redissolution of phosphate from sediments is an indicator of an eutrophic lake and contradicts the oligo- to mesotrophic character of the epilimnion.

This work shows that the oxidation of methane is the cause of the observed hypolimnic anaerobiosis and leads to the conclusion that at least part of the methane production must originate from allochthonous sources.

\section{Results}

The following parameters have been investigated in 1975/76 monthly in the central basin of the lake: Temperature and Eddy diffusion: Seasonal hypolimnic temperature developments are shown in figure 6. The Eddy diffusion coefficients $\left(\mathrm{K}_{\mathrm{z}}\right)$ at the upper boundary of the hypolimnion compartment $(645 \mathrm{~m}$ above sealevel $=45 \mathrm{~m}$ below the lake surface in summer) have been calculated according to chapter 2.4 and are shown in table 1 .

Oxygen: Figures 8 and 20 show seasonal changes of hypolimnic oxygen concentrations. In winter, full overturn enables $\mathrm{O}_{2}$-saturation in all depths. During stagnation the lowest part of the hypolimnion (620$625 \mathrm{~m}$ above sealevel) is rapidly depleted of oxygen, resulting in large concentration gradients. In the upper part of the hypolimnion gradients stay much smaller.

Methane: Figures 13 and 17 show the seasonal development of methane concentrations and rates of microbial methane consumption in the lowest hypolimnion. They show that methane accumulation and methane consumption in the water body are restricted to a period between August and February. Maximum consumption rates do not correspond with maximum methane concentrations. The massive increase of methane consumption in January is due to the $\mathrm{O}_{2}$-invasion into the deepest hypolimnion (see fig. 8).

Methane flux at the sediment-water interface: The flux has been measured directly with 'diffusion caps' (construction: see fig.4) in late spring, when no methane was observed in the hypolimnion. The measured fluxes amounted to $2.0-2.3 \mathrm{mmole} \mathrm{CH}_{4} / \mathrm{m}^{2}$. day (see chapters 2.3 and 3.4 ). From figure 16 , showing the methane concentrations in the uppermost $60 \mathrm{~cm}$ of the sediment (method: see chapter 2.2 and fig. 3), a molecular methane diffusion rate of $1 \mathrm{mmole} \mathrm{CH}_{4} / \mathrm{m}^{2}$. day has been estimated.

This leads to the conclusion that one half of the methane penetrating the sediment-water interface is of recent origin and that the other half is of older origin.

Determination of $\mathrm{C}_{14}$-activity of collected methane resulted in an age of $6270 \pm 90$ years. Again this activity may result from a mixture of $50 \%$ recently produced and $50 \%$ fossile methane.

Methane consumption at the sediment-water interface: In April the capacity of methane consumption of the uppermost $7 \mathrm{~mm}$ of the sediment has been measured (100-150 $\mathrm{mmole} \mathrm{CH}_{4} / \mathrm{m}^{2}$. day). This indicates that under favourable $\mathrm{O}_{2}$-conditions the measured flux of methane $\left(2 \mathrm{mmole} / \mathrm{m}^{2}\right.$. day $)$ can easily be consumed in the sediment-water interface.

$\mathrm{O}_{2}$-consumption due to methane oxidation: Methane oxidation has been formally separated into two steps: 1. reaction I for energy gain $\left(\mathrm{CH}_{4}+2 \mathrm{O}_{2}=\mathrm{CO}_{2}+2 \mathrm{H}_{2} \mathrm{O}\right)$. 2. reaction II for biomass-synthesis $\left(\mathrm{CH}_{4}+0.875 \mathrm{O}_{2}=\mathrm{CH}_{2.5} \mathrm{O}^{\prime}+0.75 \mathrm{H}_{2} \mathrm{O}\right)$. For further explanations see chapter 3.6.

Figure 18 shows that the $\mathrm{CO}_{2}$-production per mole consumed methane decreases with advancing stagnation.

The amounts of oxygen consumption by methane oxidation in the central basin are listed in table 7 . 
Mineralization of organic carbon in the sediment: Figure 19 shows the fraction of non volatile organic carbon (TOC) per sediment dry weight (mean value below $2.5 \mathrm{~cm}$ below the sediment surface: $3 \% \mathrm{TOC}$ / dry weight). The figure also shows the TOC-fraction of a sediment trap experiment just above the sediment surface (4.64 TOC/dry weight).

It is concluded from these results that one third of the sedimented organic particles (in terms of TOC) has been converted to volatile substances $\left(\mathrm{CO}_{2}, \mathrm{CH}_{4}\right)$ and that two thirds stay refractory.

\section{Discussion}

In order to understand the combined effects of various oxygen sinks a mathematical model considering the following $\mathrm{O}_{2}$-sinks (see fig. 21 ) was developed:

$\mathbf{J}=$ direct oxidation of organic sedimenting particles in the free water of the hypolimnion compartment (620-645 $\mathrm{m}$ above sealevel, see fig. 5), expressed in $\mathrm{O}_{2}$-equivalents per (time $\times$ volume).

$\mathrm{J}_{\mathrm{z}}=$ oxidation of organic particles sedimented in the depth $\mathrm{z}$ (see fig. 22), expressed in $\mathrm{O}_{2}$-equivalents per (time $\times$ area).

$M_{s}, M_{m}=$ oxidation of methane at the sediment-water interface, expressed in $\mathrm{O}_{2}$-equivalents per (time $\times$ area). $M_{s}=$ oxidation of recently produced methane, $M_{m}=$ oxidation of fossile methane.

$\mathrm{S}=$ oxidizable particles falling through the upper boundary of the hypolimnion compartment (in $645 \mathrm{~m}$ above sealevel), expressed in $\mathrm{O}_{2}$-equivalents per (time $\times$ area).

The sinks are connected by the following equations:

$\mathrm{S}=\mathrm{J}_{\mathrm{z}}+\mathrm{J} \cdot \mathrm{z}+\mathrm{M}_{\mathrm{s}}$ and $\mathrm{S}_{\mathrm{tot}}=\mathrm{S}+\mathrm{M}_{\mathrm{m}}$. In the model horizontal $\mathrm{O}_{2}$-transport is assumed as infinitely fast. The vertical $\mathrm{O}_{2}$-transport (in terms of Eddy diffusion) is defined in chapter 2.4 and is based on the parameters ' $\mathrm{K}_{\mathrm{z}}$ ' and ' $\mathrm{O}_{2}$-concentration gradient'. The one-dimensional model is based on the dimensions and values of figures 5,21 and 22 .

If the vertical $\mathrm{O}_{2}$-transport and the sinks $\mathrm{J}, \mathrm{S}$ and $\mathrm{M}_{\mathrm{m}}$ are known, the decrease of $\mathrm{O}_{2}$-concentrations in the vertical profile during stagnation periods can be calculated in each box of the hypolimnion compartment (see fig. 5).

Model calculations (see fig. 24) have shown that the oxygen regime in Lake Lungern can be predicted from 1 March to 1 November by assuming the following values for the various oxygen sinks mentioned: $\mathrm{S}=210, \mathrm{M}_{\mathrm{m}}=64 \mathrm{mg} \mathrm{O}_{2} / \mathrm{m}^{2}$. day and $\mathrm{J}=5.5 \mathrm{mg} \mathrm{O}_{2} / \mathrm{m}^{3}$. day. The typical $\mathrm{O}_{2}$-profiles observed (see fig. 20) can only be simulated with $\mathrm{K}_{\mathrm{z}} \leq 0.01 \mathrm{~cm}^{2} / \mathrm{sec}$.

$\mathrm{M}_{\mathrm{m}}$, the oxidation of fossile methane, is derived from direct measurements of the methane fluxes. $J$, the oxidation of sedimenting particles in the free water, agrees well with the assumption that only $20 \%$ of photosynthetically fixed organic particulate carbon fall into the hypolimnion, 50\% of which are mineralized while falling through the hypolimnion of $25 \mathrm{~m}$ depth. If $\mathrm{J}$ is assumed as independent of the depth $\mathrm{z}$, it amounts to

$$
\frac{40 \mathrm{mg} \mathrm{C} / \mathrm{m}^{2} \cdot \text { day }}{25 \mathrm{~m}} \cdot 3.47 \mathrm{mg} \mathrm{O}_{2} / \mathrm{mg} \mathrm{C}=5.5 \mathrm{mg} \mathrm{O} \text {-equivalents } / \mathrm{m}^{2} \cdot \text { day. }
$$

$\mathrm{S}$, the amount of oxidizable particles falling into the hypolimnion, has not been measured directly. It has been estimated by adjusting computer simulation to observed data (see fig. 24).

Figure 23, which compares the observed net $\mathrm{O}_{2}$-consumptions in the hypolimnic boxes (see fig. 5) with their corresponding ratios between box-volume and adjacent sediment area, indicates that $\mathrm{O}_{2}$-consumption in the lowest hypolimnion takes place primarily at the sediment-water boundary, while in the upper hypolimnion the $\mathrm{O}_{2}$-regime is affected primarily by volume sinks.

In times of sufficient $\mathrm{O}_{2}$-supply all of the invading methane, either produced in the recent sediment or of fossile origin, is consumed at the sediment-water interface. In fall the advancing anaerobiosis causes a decrease of the redox potential in the upper sediment layers and enables a temporary increase of methane production (an average of $3.7 \mathrm{mmole} \mathrm{CH}_{4} / \mathrm{m}^{2}$. day from November to January). The low redox potential inhibits methane oxidation at the sediment-water boundary. Consequently methane accumulates in the free water above the sediment. Some of the methane is oxidized within zones of simultaneous presence of $\mathrm{O}_{2}$ and $\mathrm{CH}_{4}$. This methane oxidation in the free water is, for a limited period in the annual cycle from November until February, a very important $\mathrm{O}_{2}$-sink (up to $17 \mathrm{mmole} \mathrm{CH}_{4}$ consumed/ $\mathrm{m}^{2}$-day) and delays at the beginning of full overturn the $\mathrm{O}_{2}$-saturation of the water in the deepest hypolimnion.

The simulations with the mathematical model illustrate that, without the oxidation of fossile methane, even the deepest zones of the central basin would never become anaerobic (see fig. 24 and 25). 


\section{RÉSUMÉ}

Le lac préalpin de Lungern montre, en dépit de son faible taux de production primaire $\left(120 \mathrm{~g} \mathrm{C} / \mathrm{m}^{2} \cdot\right.$ an $)$ et d'une circulation totale hivernale, un épuisement complet de l'oxygène dans le fond de l'hypolimnion (65-70 $\mathrm{m}$ au-dessous de la surface), vers la fin de la stagnation estivale.

Des examens périodiques des concentrations de $\mathrm{O}_{2}$ et $\mathrm{CH}_{4}$, des taux d'oxydation du $\mathrm{CH}_{4}$ et de la température dans le profil vertical du lac pendant les années 1975/76, ont permis une évaluation de la balance d' $\mathrm{O}_{2}$ dans le lac de Lungern.

La mesure directe du flux de $\mathrm{CH}_{4}$ à la surface du sédiment et les concentrations de $\mathrm{CH}_{4}$ dans le sédiment, aussi bien que la détermination de l'âge des bulles de méthane, portent à la conclusion que l'épuisement de l'oxygène de l'hypolimnion est dû en partie à l'oxydation du méthane fossile, qui a pénétré dans le lac par en-dessous.

Les différents «oxygen sinks» ont été déterminés par un modèle de diffusion mathématique pour la période de stagnation:

- $5,5 \mathrm{mg} \mathrm{O}_{2} / \mathrm{m}^{3}$.jour sont consumés par l'oxydation des particules autochtones organiques tombant à travers la masse d'eau.

- $77 \mathrm{mg} \mathrm{O} \mathrm{O}_{2} / \mathrm{m}^{2}$.jour sont consumés par l'oxydation du méthane proventant des particules sédimentées (flux traversant la surface du sédiment).

- $64 \mathrm{mg} \mathrm{O} / \mathrm{m}^{2}$.jour sont consumés par l'oxydation du méthane fossile (flux traversant la surface du sédiment).

D'autres calculs montrent que l'anaérobie observée dans l'hypolimnion profond n'apparaîtrait jamais sans l'oxydation du méthane fossile.

\section{LITERATURVERZEICHNIS}

1 Alsterberg, G.: Die Winklersche Bestimmungsmethode für in Wasser gelösten, elementaren Sauerstoff sowie ihre Anwendung bei Anwesenheit oxidierbarer Substanzen. Biochem. Z. 170, 30 (1926).

2 Ambühl, H.: Die praktische Anwendung der elektrochemischen Sauerstoffbestimmung im Wasser. Schweiz. Z. Hydrol. 22, 23-39 (1960).

3 Baas-Becking, B. L.: The role of hydrogen and oxygen in the inorganic environment. Acta biotheor. (Leiden) 12, 71-80 (1957).

4 Bossard, P.: Der Sauerstoff- und Methanhaushalt im Lungernsee. Diss. ETH, Nr. 6794, 1981.

5 Bossard, P., Joller, T., und Szabó, E.: Die quantitative Erfassung von Methan im Seewasser. Schweiz. Z. Hydrol. 43, im Druck (1981).

6 Bloesch, J.: Sedimentation und Phosphorhaushalt im Vierwaldstättersee (Horwer Bucht) und im Rotsee. Schweiz. Z. Hydrol. 36, 71-186 (1974).

7 Bührer, H.: Die Berechnung der totalen Menge gelöster Stoffe in Seen. Schweiz. Z. Hydrol. 4l, 418420 (1979).

8 Cappenberg, Th.E.: Studies on the ecology of sulfate reducing and methane producing bacteria in the mud. Verh. int. Verein. Limnol. (Leningrad) 18, 1300 (1973).

9 Cappenberg, Th.E.: Relationship between sulfate reducing and methane producing bacteria. Pl. Soil 43, 125-139 (1975).

10 Cooper, L.H.N.: The role of liberation of phosphate in sea water by breakdown of plankton organisms. J. mar. biol. Ass. U.K. 20, 197-200 (1935).

11 Das Lungernseewerk der CKW in Luzern. In: Führer durch die schweizerische Wasser- und Elektrizitätswirtschaft, Bd.2, III. Ausgabe, 1949.

12 Deuser, W.G., Degens, E.T., und Harvey, G.R.: Methane in Lake Kivu: new data bearing in its origin. Science 181, 51-54 (1973).

13 Dostalek, M.: Wachstumscharakteristiken von Kohlenwasserstoffbakterien. Čslká Biol. 3, 99-107 (1954)

14 Dworkin, M., und Foster, J.W.: Studies on Pseudomonas methanica nov. comb. J. Bact. 72, 646-659 (1956).

15 Foster, J.W., und Davis, R.H.: A methanedependent coccus, with notes on classification and nomenclature of obligate methane-utilizing bacteria. J. Bact. 91, 1924-1931 (1966). 
16 Fuhs, W.: Sammelbericht: der mikrobielle Abbau von Kohlenwasserstoffen. Arch. Mikrobiol. 39 , 374-422 (1961).

17 Gächter, R.: Sarnerseeuntersuchungen 1972. Nicht publiziert.

18 Gächter, R., und Bossard, P.: Bericht über die physikalischen, chemischen und biologischen Untersuchungen des Lungernsees im Jahre 1971. Nicht publiziert (EAWAG-interner Bericht, 1974).

19 Geologischer Führer der Schweiz, Heft 7, S.617-622. Wepf + Co., Basel 1967.

20 Grim, J.: Beobachtungen am Phytoplankton des Bodensees (Obersee) sowie deren rechnerische Auswertung. Int. Rev. Hydrobiol. Hydrogr. 39, 193-315 (1939).

21 Harvey, H.W.: The chemistry and fertility of sea waters. Cambridge University Press, London 1955.

22 Harwood, J.H., und Pirt, S.J.: Quantitative aspects of growth of the methane oxidizing bacterium Methylococcus capsulatus on methan in shake flask and continuous chemostat culture. J. appl. Bact. 35, 597-607 (1972).

23 Hess, P. und O.: Der wandernde See von Lungern. Buchdruckerei Louis Ehrli, Sarnen 1935.

24 Imboden, D.: Interstitial transport of solutes in non-steady state accumulating and compacting sediments. Earth Planet. Sci. Lett. 27, 221-228 (1975).

25 Imboden, D., und Emerson, S.: Study of transport processes through the sediment-water interface in lakes using natural radon-222. In: Proceedings of SIL-Symposium, Interaction between sediments and fresh waters. Amsterdam, September 1976.

26 Kleerekoper, H.: The mineralisation of Plankton. J. Fish. Res. Bd Can. 10, 283-291 (1953).

27 Kvasnikov, E. I., et al.: The methods of isolation and some biological peculiarities of gas oxidizing microorganisms. Mikrobiologija (Moskau) 38, 231-257 (1969).

28 Leadbetter, E.R., und Foster, J.W.: Studies on some methane utilizing bacteria. Arch. Mikrobiol. 30, 91-118 (1958).

29 Li, Y.-H.: Vertical eddy diffusion coefficient in Lake Zürich. Schweiz. Z. Hydrol. 35, 1-7 (1973).

30 Naguib, M.: On methane oxidizing bacteria in fresh waters. Part I, Z. allg. Mikrobiol. 10, 17-36 (1970); part II, Z. allg. Mikrobiol. 10, 627-636 (1970).

31 Naguib, M.: On methane oxidizing bacteria in fresh waters. Part III, Z. allg. Mikrobiol. 11, 39-47 (1971).

32 Naguib, M.: Über methanoxidierende Bakterien in Binnengewässern und deren mögliche ökonomische Bedeutung. Verh. int. Verein. Limnol. (Leningrad) I8, 1287-1299 (1973).

33 Naguib, M.: A rapid method for the quantitative estimation of dissolved methane and its application in ecological research. Arch. Hydrobiol. 82, 60-73 (1978).

34 Ohle, W.: Die Stoffwechseldynamik der Seen in Abhängigkeit von der Gasausscheidung ihres Schlammes. Vom Wass. 25, 127-149 (1958).

35 Ohle, W.: Chemische und mikrobiologische Aspekte des biogenen Stoffhaushaltes der Binnengewässer. Mitt. int. Verein. Limnol. 14, 122-133 (1968).

36 Oremland, R.S.: Methane production in shallow-water, tropical marine sediments. Appl. Microbiol. 30/4, (1975).

37 Overbeck, J.: Über Anreicherung und Isolierung methanoxidierender Bakterien aus dem Süsswasser. Symposium der deutschen Gesellschaft für Hygiene und Mikrobiologie e.v.: Anreicherungskultur und Mutantenauslese. Zentbl. Bakt., Suppl. 1, 139-147 (1964).

38 Overbeck, J., und Ohle, W.: Contributions to the biology of methane oxidizing bacteria. Verh. int. Verein. Limnol. 15, 535-543 (1964).

39 Redfield, A.C., et a1.: The influence of organisms on the composition of seawater. In: M.N. Hill (Hrsg.): The Sea, Bd.II, S. 26-77. Interscience Publications, New York 1963.

40 Reeburgh, W. S.: Methane consumption in Cariaco Trench waters and sediments. Earth Planet. Sci. Lett. 28, 337-344 (1976).

41 Rissanen, K., und Miettinen, J.K.: Use of mercury compounds in agriculture and its implications. In: Mercury contamination in man and his environment, S. 5-24. IAEA, Vienna, STI/DOC/10/137, 1972.

42 Rossolimo, L.O., und Kuznecova, S.: Die Boden-Gasausscheidung als Faktor des Sauerstoffhaushaltes der Seen. Arb. Limnol. Stat. Kossino 17, 87-112 (1934).

43 Rossolimo, L.L.: Die Boden-Gasausscheidung und das Sauerstoffregime der Seen. Verh. int. Verein. Limnol. (Belgrad), S.539-561 (1935).

44 Rudd, J.W., et al: Measurement of microbial oxidation of methane in lake water. Limnol. Oceanogr. 19, 519-524 (1974). 
45 Rudd, J.W., und Hamilton, R.D.: Factors controlling rates of methane oxidation and the distribution of methane oxidizers in a small stratified lake. Arch. Hydrobiol. 75/4, 522-538 (1975).

46 Rudd, J.W., und Hamilton, R.D.: Two samplers monitoring dissolved gases in lake water and sediments. Limnol. Oceanogr. 20, 902-906 (1975).

47 Rudd, J.W., et al.: Factors controlling methane oxidation in shield lakes. Limnol. Oceanogr. 21, 357-364 (1976).

48 Rudd, J.W., und Hamilton, R.D.: Methane cycling in a eutrophic shield lake and its effects on whole lake metabolism. Limnol. Oceanogr. 23, 337-348 (1978).

49 Rudd, J.W.: Methane Oxidation in Lake Tanganyika (East Africa). Limnol. Oceanogr. 25, 958-963 (1980).

50 Schweizerisches Lebensmittelbuch, 4. Aufl., 1937.

51 Soehngen, N.L.: Über Bakterien, welche Methan als Kohlenstoffnahrung und Energiequelle gebrauchen. Zentbl. Bakt., Il.Abt. 15, 513-517 (1906).

52 Staub, E.: Biologisch-stratigraphische Untersuchungen an jungen Sedimenten des Vierwaldstättersees. Diplomarbeit an der ETH, 1974; nicht publiziert.

53 Swisspetrol, mündliche Mitteilung.

54 Verordnung über Abwassereinleitungen (vom 8.Dezember 1975) der Schweizerischen Eidgenossenschaft.

55 Whittenburg, R., et al: Enrichment, isolation and some properties of methane-utilizing bacteria. J. gen. Microbiol. 61, 205-218 (1970).

56 Winkler, L.W.: Die Bestimmung des im Wasser gelösten Sauerstoffes und die Löslichkeit des Sauerstoffes im Wasser. Ber. dt. chem. Ges. 21, 2843 (1888); 22, 1764 (1889).

57 Wirz U.E.: Untersuchungen über vertikale Diffusionsprozesse im Bielersee. Lizentiatsarbeit an der Universität Bern, 1978, nicht publiziert.

58 Yamamoto, S., et al.: Solubility of methane in distilled water and seawater. J. Chem. Enging Data 21/1, 78-80 (1976).

Adresse der Autoren: Dr. Peter Bossard, Dr. René Gächter, Seenforschungslaboratorium der EAWAG/ ETH, CH-6047 Kastanienbaum. 